\title{
Immune-mediated mechanisms of atherosclerosis and implications for the
} clinic

Meritxell Nus ${ }^{1}$ and Ziad Mallat ${ }^{1}$

${ }^{1}$ Division of Cardiovascular Medicine, Dept. of Medicine, University of Cambridge, United Kingdom.

\begin{abstract}
Introduction: A large body of evidence supports the inflammatory hypothesis of atherosclerosis. And both innate and adaptive immune responses play important roles in all disease stages.

Areas covered: Here, we review our understanding of the role of the immune response in atherosclerosis, focusing on the pathways currently amenable to therapeutic modulation. We also discuss the advantages or undesirable effects that may be foreseen from targeting the immune response in patients at high cardiovascular risk, suggesting new avenues for research.

Expert commentary: There is an extraordinary opportunity to directly test the inflammatory hypothesis of atherosclerosis in the clinic using currently available therapeutics. However, a more balanced interpretation of the experimental and translational data is needed, which may help address and identify in more detail the appropriate settings where an immune pathway can be targeted with minimal risk.
\end{abstract}

Keywords: Innate immune response, adaptive immune response, atherosclerosis, anti-inflammatory therapies. 


\section{Abbreviations}

Cardiovascular (CV)

Low-density lipoproteins (LDL)

Pathogen associated molecular patterns (PAMPs)

Damage-associated molecular patterns (DAMPs)

Pattern recognition receptors (PRR)

Dendritic cells (DC)

Immunoglobulins (Ig)

$\mathrm{T}$ cell receptors (TCR)

Oxidized-LDL (oxLDL)

High-sensitivity C-reactive protein (hsCRP)

Endothelial cells (EC)

Smooth muscle cells (SMC)

IL1-receptor type-I (IL1R1)

Mitochondrial uncoupling protein (UCP)

IL1R accessory protein (IL1RAP)

myeloid differentiation factor 88 (MyD88)

c-Jun $\mathrm{N}$ terminal kinases (JNKs)

Extracellular signal-regulated kinases (ERKs)

Mitogen-activated protein kinases (MAPKs)

IL1R antagonist (IL1Ra)

Macrophage colony-stimulating factor (M-CSF)

Bone marrow transplantation (BMT)

Acute coronary syndromes (ACS)

Coronary artery disease (CAD)

Oxidized phospholipids (OxPL)

Rheumatoid arthritis (RA)

Subcutaneous (s.c.)

Canakinumab Anti-Inflammatory Thrombosis Outcomes Study (CANTOS)

Methotrexate (MTX)

5-aminoimidazole-4carboxamide ribonucleotide (AICAR)

lectin-like oxidised LDL receptor -1 (LOX1)

Cardiovascular Inflammation Reduction Trial (CIRT)

Acute phase response (APR)

Suppressor of cytokine signaling 3 (SOCS3)

Lipoprotein a (Lp(a))

Platelet-activator factor factor (PAF)

Lysophosphatidylcholine (LysoPC)

Stabilization of Atherosclerosis Plaque by Darapladib Initiation of Therapy

(STABILITY)

Stabilization of Plaques Using Darapladib-Thrombolysis in MI 52 Trial (SOLIDTIMI 52)

Fewer Recurrent Acute coronary events with Near-term Cardiovascular

Inflammation Suppression (FRANCIS)

Antigen presenting cells (APC)

Major histocompatibility complex class II molecule (MHCII)

T regulatory (Tregs)

Retinoic acid orphan receptors (ROR) 
Naturally occurring Tregs (nTregs)

Adaptive/induced Treg cells (iTreg) 


\section{Introduction}

Atherosclerosis is responsible for most ischemic cardiovascular (CV) diseases and is a leading cause of death and morbidity worldwide. Atherosclerosis is a complex arterial pathology with multiple genetic and environmental risk factors, initiated in response to trapping of low-density lipoproteins (LDL) in the intima and their acquisition of immunogenic properties through both enzymatic and non-enzymatic (oxidative) modifications. The subsequent immune response involves interactions between many vascular and circulating cells and mediators, and frequently leads to a chronic inflammatory state due at least in part to defects in counter-regulatory mechanisms. Broad evidence supports the inflammatory theory of atherosclerosis, and immune cells have been shown to participate in all stages of the disease from its initiation to progression and plaque rupture or erosion.

An innate immune response is initiated by the recognition of signature molecules that the organism considers as carrying a danger. Those molecules can be of microbial origin (i.e. pathogen associated molecular patterns or PAMPs) or selfmolecules that are only secreted or exposed to the immune system in case of cell injury or death (i.e. damage-associated molecular patterns or DAMPs). Following recognition through germline encoded receptors (called pattern recognition receptors PRR) expressed in innate immune cells (e.g., monocytes/macrophages, neutrophils, dendritic cells (DC), NK cells, B1 cells), PAMPs and DAMPs activate protective responses leading to the killing of the microbe or the clean-up and repair of dead tissue.

The adaptive immune response is induced by other types of molecules (i.e. antigens), which are recognized by highly selected, clonally developed and specific antigen receptors, e.g., immunoglobulins (Ig) in B cells, and T cell receptors (TCR) in T cells. Antigen recognition in combination with additional signals delivered by co-stimulatory molecules and soluble mediators, lead to the proliferation and differentiation of lymphocytes into antigen-specific effector cells helping to eradicate the aggression.

When the stimuli are persistent (as it may be the case for oxidized-LDL (oxLDL) or cholesterol crystals in atherosclerosis), continued innate and adaptive immune activation will promote chronic inflammation, damaging the tissues and leading to disease. Patients with elevated inflammatory biomarkers such as high-sensitivity C-reactive protein (hsCRP) have increased CV risk, and recent work directly implicates both the innate and adaptive immune pathways in the development and complications of human atherosclerosis. Yet, it remains unknown whether targeted inhibition of immune responses will reduce CV event rates. In the present review we will discuss the role of selective innate and adaptive immune responses in atherosclerosis. We will focus on currently targeted pathways, and pathways that are susceptible to be targeted by available drugs; we will explain how this basic and experimental knowledge may be translated to the clinic with the aim to develop better therapies and reduce disease burden.

\section{Therapies targeting the innate immune response}

\section{IL1 pathway}


Pathophysiological pathway: The IL1 family of cytokines comprises 11 proteins, encoded by different genes, which initiate and regulate inflammatory processes [1]. The founding members are IL1 $\alpha$ and IL1 $\beta$, which exert the most potent proinflammatory effects. They are mainly produced by monocytes and macrophages but also in lower amounts by neutrophils, keratinocytes, epithelial and endothelial cells (EC), lymphocytes, smooth muscle cells (SMC) and fibroblasts. Despite IL1 $\alpha$ and IL1 $\beta$ only showing a $24 \%$ amino acid sequence homology, they display largely identical biological functions. They both bound to the same surface receptor, called IL1-receptor type-I (IL1R1), which is ubiquitously expressed.

IL1 $\alpha$ is synthesized as a 33kDa precursor peptide (proIL $1 \alpha$ ) that can be cleaved by the activation of the calcium-dependent membrane-associated cysteine protease calpain to produce an active $17 \mathrm{kDa}$ peptide with full biological activity [2]. IL1 $\alpha$ activation depends on the cell type and IL1 $\alpha$ is up to 50 fold times more active than proIL1 $\alpha$ due to increased IL1R1 affinity for IL1 $\alpha$ [3]. In some cells, there is also an IL1R2 that binds to proIL1 $\alpha$ impairing calpain-mediated cleavage. However, following inflammasome activation, caspase- 1 specifically cleaves IL1R2 and restores full IL1 $\alpha$ activity [3]. An inflammasome-independent mechanism of IL1 $\alpha$ production was also described recently. Fatty acids selectively stimulated the release of IL1 $\alpha$ in macrophages by a mechanism involving the mitochondrial uncoupling protein (UCP)2 [4]. Interestingly, UCP2 in turn may promote inflammasome-dependent caspase-1 activation and IL1 $\beta$ production through modulation of de novo fatty acid synthesis [5].

IL1 $\beta$ is synthesized as a biologically inactive $31 \mathrm{kDa}$ precursor peptide (proIL1 $\beta$ ) (extensively reviewed in [6]). Pro-IL1 $\beta$ must be cleaved, mainly by caspase-1, to generate an active $17 \mathrm{kDa}$ peptide and to exert its function. Caspase- 1 is regulated by a multiprotein oligomer, known as inflammasome, which acts as a sensor of the innate immune response. Activation of NLRP3 inflammasome can be induced by particulate ligands (i.e. cholesterol crystals in atherosclerosis) [7] or soluble ligands (i.e. oxidized LDL) converted intracellularly into crystals [8].

IL1 $\alpha$ and/or $\beta$ binding to IL1R1 induces the recruitment of a second receptor chain called IL1R accessory protein (IL1RAP) to the intracellular domain of IL1R1. The IL1 $\alpha$ or $\beta$ )-IL1R1-IL1RAP ternary complex recruits several intracellular adaptor proteins to trigger a signaling cascade that activates pro-inflammatory transcription factors (reviewed in [1]). As a result, IL1 signaling leads to the activation of several target genes like pro-inflammatory molecules (e.g.. TNF $\alpha$, IL6, IL8, etc.), EC adhesion molecules, and macrophage colony-stimulating factor (CSF1), etc.

IL1R antagonist (IL1RN) is a major natural competitive inhibitor of the binding of IL1 to its receptor. Despite the same affinity of IL1 and IL1RN for IL1R1, there is a need for a large molar excess of IL1RN (100 to 1000-fold) to block IL1 activity IL1R antagonist (IL1RN) is a major natural competitive inhibitor of the binding of IL1 to its receptor. Despite the same affinity of IL1 and IL1RN for IL1R1, there is a need for a large molar excess of IL1RN (100 to 1000-fold) to block IL1 activity [6]. Experimental evidence: A role for IL1 has been described in both early [9-11] and advanced [12,13] atherosclerosis. At the early stages of fatty streaks formation, exogenous administration [9] of IL1RN or its genetic overexpression $[10,11]$ decreases atherosclerotic plaque formation in murine models. Apoe $/$ mice lacking IL1RN develop a severe form of aortic inflammation with massive macrophage infiltration in the adventitia, macrophage lipid accumulation, and 
marked destruction of the aortic lamina [11]. This effect is not observed in $1 / 1 \mathrm{rn} \%$ mice on $\mathrm{Apoe}^{+/+}$background, suggesting that the lack of IL1RN is not sufficient to promote arteritis in normo-cholesterolemic animals.

In contrast, the role of IL1 signaling in more advanced stages of atherosclerosis remains debated. For example, plaque size did not differ between $A p o e^{/-} / I L 1 r 1^{+/+}$ and $A$ poe $\% / I l 1 r 1 \%$ mice but the latter developed more unstable-appearing plaques, as revealed by reduced collagen and SMC accumulation and increased occurrence of intraplaque haemorrhage [12]. Thus, animal models of atherosclerosis have shown a dual role for IL1, pro-atherogenic at early stages, but potentially protective (enhancing plaque stability) at advanced stages. IL1R1 and IL1RN respectively mediate and inhibit both IL1 $\alpha$ and IL1 $\beta$, but whether the 2 forms of IL1 exhibit similar or contrasting roles in atherosclerosis is still under intense investigation.

C57Bl6 $\mathrm{Il} 1 \mathrm{~b} \%$ mice showed decreased atherosclerotic plaques after high fat diet. The same atheroprotective effect was observed in $I 11 \mathrm{a} \%$ despite increased nonHDL-cholesterol levels. Bone marrow transplantation (BMT) from $I l 1 a^{\%}$ mice into WT mice did not alter lipoprotein levels but still decreased atherosclerotic plaque formation. However, BMT from $I l 1 b^{\%}$ did not affect plaque size [14]. Thus only IL1 $\alpha$ secretion from bone marrow-derived cells appears to be atherogenic. This conclusion is supported by recent data obtained in $L d l r^{-} /$mice [4]. Nevertheless, treatment with monoclonal antibodies against IL1 $\beta$ (XOMA 052) in atherosclerotic mice, significantly decreased atherosclerotic plaque formation associated with reduced non-HDL/HDL ratio, plaque lipid content and macrophage infiltration [15].

Translational studies: In the late 80's several in vitro experiments using human cell cultures suggested a potential role of IL1 $\beta$ in atherosclerosis. In vitro IL1 $\beta$ regulates SMC mitogenesis [16], induces leukocyte adhesion to the endothelium [17], modulates LDL oxidation [18], and promotes vascular permeability [19]. Both IL1 $\beta$ and IL1 $\alpha$ were detected in human atherosclerotic plaques [20], IL1 $\beta$ being mostly released by macrophages and active IL1 $\alpha$ by SMC $[21,22]$.

IL1 is almost undetectable in blood using routine methods, so only a very few epidemiological studies are available on the relationship between circulating IL1 and CV risk [23]. Patients with greater atherosclerotic burden [24,25] presented increased IL1 $\beta$ levels, which were associated with less favorable prognosis after acute coronary syndromes (ACS) [26,27].

Two polymorphisms have been described for the IL1B gene, the frequent variant $I L 1 B^{*} 1$ (a single transition from $\mathrm{C}$ - $\mathrm{T}$ in position -511 ) and the rare variant $I L 1 B^{*} 2$ (a single transition C-T in exon 5 in position +3953). Only one study found an association between specific combinations of these polymorphisms and the risk of developing coronary artery disease (CAD) in individuals with increased oxidized phospholipids (OxPL)/apoB ratio [28]. The polymorphic region within intron 2 of the IL1 receptor antagonist gene $(I L 1 R N)$ contains a variable number of tandem repeats of 86 base pairs, with $I L 1 R N^{*} 1$ representing four repeats of the $86 \mathrm{bp}$ in tandem, $I L 1 R N^{*} 2$ having two repeats, and IL1RN*3 containing five repeats [29]. Carriers of the $I L 1 R N^{*} 2$ polymorphism release more IL1RN, which was related to reduced atherosclerotic plaque size in some European populations [30,31], but not in others [32]. Recently, another two uncorrelated variants rs6743376 and rs1542176 located upstream of IL1RN were identified as the strongest known genetic determinants of circulating IL1RN concentrations. The authors developed a 
genetic score combining the alleles of those two common variants and compared it with the effects of anakinra (recombinant IL1RN) on inflammatory biomarkers in rheumatoid arthritis (RA), diabetes mellitus type 2, coronary heart disease, stroke and aortic aneurysm in a total of 453411 participants. For each IL1RN minor allele inherited, there was a significant decrease of IL6 and hsCRP that correlated with the effect of anakinra. Interestingly, individuals with increased number of inherited minor alleles (corresponding to higher IL1RN levels) showed decreased risk of RA but, surprisingly, increased CV risk (CAD, ischemic stroke and abdominal aortic aneurysm) [33]. IL1RN minor alleles were also associated with a significant increase of circulating lipoproteins like LDL-cholesterol. However, the latter only explained $33 \%$ of the increase in CV risk associated with IL1RN genotype. Thus, similarly to experimental data, translational human data remain inconclusive regarding the direct role of IL1 the pathogenesis and complications of CV diseases. Clinical trials: During the last 15 years several molecules have been used to modulate IL1 pathway in autoimmune and chronic inflammatory diseases. Anakinra was the first selective inhibitor of IL1 pathway approved by the FDA to treat several autoinflammatory diseases like RA [34] and it is now undergoing clinical trials to treat other immune-mediated diseases. The effect of anakinra in CV disease was tested in a Phase II, multi-center, placebo-controlled trial, comparing the administration of a subcutaneous (s.c.) daily injection of anakinra (100 mg) for 14 consecutive days in non-ST elevation ACS patients. Anakinra significantly decreased CRP levels compared to placebo during the treatment period. However, a rebound of CRP was observed after treatment discontinuation in the anakinra group. Furthermore, major adverse cardiac events were significantly increased in the anakinra group after 1 year of follow-up [35]. Another important limitation of anakinra is its short-half life requiring frequent injections or high doses, which may be very inconvenient for the patient.

Owing to its specificity and long half-life, antibody-based neutralization of IL1 $\beta$ is emerging as a more attractive therapeutic strategy. Canakinumab, is a specific IL1 $\beta$ neutralizing monoclonal antibody that has recently been approved by the FDA for the treatment of several auto-inflammatory diseases (i.e. cryoporin-associated periodic syndromes). It is being tested in the Canakinumab Anti-Inflammatory Thrombosis Outcomes Study (CANTOS), which is currently testing the impact of IL1 $\beta$ inhibition as compared to placebo on recurrent CV events (MI, stroke, and CV death). Stable post-myocardial infarction (MI) CAD patients who remained at high $\mathrm{CV}$ risk as revealed by persistent elevations of CRP ( $>2 \mathrm{mg} / \mathrm{L})$ despite contemporary secondary prevention strategies have undergone random assignment to s.c. canakinumab $50 \mathrm{mg}, 150 \mathrm{mg}$ or $300 \mathrm{mg}$ or placebo every 3 months (in addition to standard pharmacological treatment). This trial is conducted in more than 40 countries worldwide in 146 centers and will recruit 17,400 patients [36]. Pilot data are available from 556 men and women who were randomly allocated to s.c. placebo or canakinumab $(5,15,50$ or $150 \mathrm{mg}$ monthly) and followed up for 4 months. There were dose-dependent and significant decreases of hsCRP, IL6 and fibrinogen levels in canakinumab-treated patients compared to placebo [37]. However, there was also a modest but significant increase in circulating triglycerides levels related to the high doses of canakinumab, which might offset, at least in part, the favorable anti-inflammatory profile. The effect of canakinumab on major CV events will be reported in 2017. 
Colchicine, a natural component originally extracted from plants (genus Colchicum) that has been used to treat gout for centuries, is now also being considered for the treatment of atherosclerotic disease. Gout is an inflammatory disease characterized by the deposit of sodium urate crystals that act as DAMPs and activate the inflammasome/IL1 $\beta$ pathway. Colchicine inhibits inflammasome activation in neutrophils as it forms a tubulin-colchicine complex that prevents the formation of microtubules [38]. Microtubules are necessary for the transport of NLRP3 to the mitochondria for correct assembly of the inflammasome. Since cholesterol crystals activate the inflammasome pathway in a manner very similar to urate crystals, colchicine is now considered as potentially useful in treating CAD and acute CV events. Short-term administration of colchicine significantly limits local (heart circulation) but not systemic production of IL1 $\beta$, IL6 and IL18 in ACS patients, suggesting a selective anti-inflammatory effect $[39,40]$. The low dose colchicine (Lo-Do-Co) clinical trial was a prospective, randomized, observerblinded endpoint design in 532 patients with stable CAD who randomly received a low dose of colchicine $(0.5 \mathrm{mg} /$ day) or placebo (besides standard pharmacological treatment) for 3 years. The addition of colchicine to these patients significantly reduced the risk of fatal CV event [41]. A recent meta-analysis of colchicine trials, including those in pericarditis, points towards an overall benefit on CV risk reduction [42]. However, it should be acknowledged that data interpretation or validity may be significantly limited by the lack of blinding, lack of placebo control, and a high rate of dropouts in patients assigned to colchicine.

\section{Methotrexate}

Pathophysiological pathway: Methotrexate (MTX) is an antimetabolite approved by the FDA for use in some neoplastic diseases, severe psoriasis and adult RA. MTX was originally designed as an antagonist for folic acid. At high doses (used for several cancers), it blocks dihydrofolic acid reductase impairing purines and pyrimidines synthesis and thereby DNA synthesis and replication of tumor cells.

In 1951, MTX was first introduced to treat RA based on the rationale that it should inhibit proliferation of leukocytes and other cells that accumulate in the inflamed joints [43]. Low doses of MTX have an anti-inflammatory effect, based on the clinical observation that they decrease the levels of pro-inflammatory mediators, but the precise anti-inflammatory mechanism is still unresolved. Several hypotheses may tie together to explain the anti-inflammatory effect of MTX:

1. Folate antagonistic action, whereby MTX may inhibit T cell proliferation at sites of joint inflammation in RA [44]. However, administration of folic and folinic acid does not decrease its anti-inflammatory effect [45].

2. Inhibition of potentially toxic transmethylation compounds leading to a decrease of polyamines. Despite polyamines having some anti-oxidative properties, their excessive accumulation and subsequent catabolism may increase the generation of toxic $\mathrm{NH}_{3}$ and $\mathrm{H}_{2} \mathrm{O}_{2}$ [46]. MTX inhibits the synthesis of tetrahydrofolate that is necessary for the synthesis of methionine, S-adenosylmethionine and downstream polyamines. However, drugs used to inhibit the formation of these polyamines like 3-deazaadenosine did not exert any positive effect on RA, mainly because a correct cellular content of polyamines is necessary for their antioxidative functions.

3. Increased concentrations of extracellular adenosine: MTX is metabolized in the liver to 7-hydroxy-MTX and converted into polyglutamated MTX. These 
polyglutamates inhibit 5-aminoimidazole-4carboxamide ribonucleotide (AICAR) formilase leading to intracellular AICAR accumulation. AICAR accumulation leads to enhance release of adenine nucleotides and their extracellular conversion to adenosine. Adenosine exhibits several anti-oxidant and anti-inflammatory effects. AICAR may also activate AMPK to inhibit macrophage inflammatory responses [47].

Despite all these potential mechanisms of action, it is still unclear how MTX exerts its anti-inflammatory response.

Experimental evidence: Evidence that MTX could be useful in the treatment of CV diseases derives from clinical trials in RA patients where MTX treatment was associated with a significant reduction of fatal CV events [48]. Paradoxically, very few experimental studies were launched to elucidate its direct role in CV disease. In one experimental study, MTX significantly decreased atherosclerotic plaque formation in rabbits fed a high cholesterol diet, and was associated with decreased macrophage migration and reduced apoptosis within the plaque [49]. In a murine model of inflammatory vasculopathy, administration of low dose MTX significantly reduced intramyocardial vasculopathy and attenuated end-organ damage. In that study, MTX up-regulated AMPK-CREB pathway in EC, activating a cytoprotective program [50].

In vitro experiments suggested that the atheroprotective role of MTX could also rely on enhanced reverse cholesterol transport and impairment of foam cell formation. Treatment of human blood monocyte-derived macrophages with MTX significantly increased adenosine, which activated 27-hydroxylase through $\mathrm{A}_{2 \mathrm{~A}}$ receptors. Increased generation of 27-hydroxycholesterol up-regulated $A B C A 1$ gene expression, possibly through LXR activation, thereby increasing reverse cholesterol transport [51]. The effect of MTX on inhibition of foam cell formation was also attributed to $A_{2 A}$ receptor stimulation by adenosine presumably decreasing lectin-like oxidised LDL receptor -1 (LOX1) expression [52].

Translational studies: Current information on MTX and CV risk derives from observational studies and clinical trials in patients with RA, psoriasis or polyarthritis treated with MTX, in whom CV events were reported. Several metaanalysis of those studies reached the same conclusion that MTX administration is associated with a significant decrease in CV events [48,53-56]. One of the largest cohort studies ( $n=16,752)$ detected a 35\% decrease in CV morbidity in the group treated with MTX compared to non-MTX treated patients after a follow-up of 4 years [57]. Another study that recruited a total of 6,707 veterans with RA on database (90\% males and 10\% females) compared the effect of low to high-dose of MTX on the incidence of CV morbidity. The study reported a 35\% significant decrease in CV morbidity on low-dose MTX, while no effect on morbidity was found in the high dose treated group [58].

Clinical trials: Based on those encouraging results and the relative security of MTX use in RA, it has been hypothesized that MTX could be beneficial to patients who do not present with RA but are at high risk of CV events. Additional advantages of MTX in the setting of CV disease include its safety profile at low doses and the fact that it does not affect lipoprotein metabolism in an unfavorable manner, as it is the case for some other anti-inflammatory drugs. The first trial, Cardiovascular Inflammation Reduction Trial (CIRT), has been funded by the NHLBI and is currently evaluating the effect of low-dose MTX (target dose, 15-20 
$\mathrm{mg} / \mathrm{wk}$ ) as compared to placebo on the reduction of major vascular events. The trial will include 7,000 patients with prior MI who are already diagnosed either with diabetes type 2 or metabolic syndrome. The primary endpoint is a composite of non-fatal MI, stroke, and CV death [59]. The trial is expected to provide an interesting complementary therapeutic strategy for the secondary prevention of CV events.

\section{IL6 pathway}

Pathophysiological pathway: IL6 is a pleiotropic cytokine with a wide range of biological activities in inflammation and immune regulation. All members of the IL6 family bind to the signal transducer of cytokines related to IL6 called glycoprotein 130 (gp130) exerting pleiotropic effects (reviewed in[60]).

IL6 binds the $80 \mathrm{kDa}$ type I transmembrane glycoprotein termed membrane IL6 receptor (mIL6R), and gp130. This complex IL6-mIL6R-gp130 activates the classical IL6 signal transduction pathway [61]. mIL6R is only expressed on the surface of some cell types like hepatocytes, neutrophils, and some types of macrophages and T cells; thus classical activation is restricted to those cells. IL6 pathway activates JAK tyrosine kinases and promotes the recruitment and phosphorylation of STAT3 to induce downstream effector responses, for example, activation of the inflammatory acute phase response (APR) (i.e., CRP and fibrinogen production) in hepatocytes [62]. This is counterbalanced by the activation of the suppressor of cytokine signaling 3 (SOCS3), which binds to gp130 inhibiting JAK activity [63]. Intriguingly however, in the absence of SOCS3, prolonged activation of STAT3 by IL6 switches downstream responses towards the activation of an anti-inflammatory program [64]. IL6 also activates IL4 receptor expression in macrophages, thus promoting their polarization into an antiinflammatory M2 phenotype [65]. Thus, depending on local cues, IL6 may exert both pro and anti-inflammatory effects.

IL6 pathway is even more complicated due to the ubiquitous expression of gp130 and the presence of a soluble IL6R, allowing trans-signaling even in the absence of the mIL6R [66]. There are two potential mechanisms that lead to the formation of sIL6R. The first one involves the proteolytic cleavage of the mIL6R and is dependent on metalloproteases of the ADAM family (specifically ADAM10 and ADAM17). The second one implies an alternative splicing mechanism of IL6R mRNA and has been described in humans but not in mice. Homodimers of gp130 are unable to activate the IL6 cascade just through binding to IL6. However, they do so in the presence of sIL6R. IL6 trans-signaling is therefore very important for cells that do not express mIL6R at any stage of development or activation. Several mechanisms related to atherosclerosis, such as $\mathrm{T}$ cell trafficking and proliferation, or activation of EC and SMC, may be independent of mIL6R but regulated through IL6 trans-signaling [67].

The glycoprotein gp130 is also present in a soluble form, mainly the result of alternative splicing [68]. Soluble gp130 can bind the IL6-sIL6R complex acting as a competitive inhibitor and impairing trans-signaling.

Classical and trans-signaling would be expected to have the same effect upon IL6 production. However, experimental results point to the activation of differential downstream responses depending on the cell type and the state of cell activation [69]. Thus, it is be very important to consider the specific contribution of classical 
and trans-activation to the development of a $\mathrm{CV}$ disease in order to propose specific and accurate therapeutic strategies.

Experimental evidence: Experiments in mice performed to study the role of IL6 in atherosclerosis have led to controversial and unexpected results. Exogenous and sometimes supra-physiological IL6 injections were reported to enhance atherosclerosis, in part due to increased oxLDL uptake by macrophages in Apoe $/$ mice [70,71]. However, Apoe $\% / / 116^{\%}$ mice presented larger and more calcified atherosclerotic plaques compared to $1 \mathrm{I6}^{+/+} / \mathrm{Apoe}^{-/}$mice after the consumption of a normal chow diet for 1 year [72]. These results were also corroborated in C57Bl6 $116 \%$ mice fed a Paigen diet for 15 weeks, which exhibited larger fatty streak lesions than their WT littermates [73]. Ldlr $\% / I 16^{\%}$ developed atherosclerotic plaques that were comparable in size to those seen in their $L d l r^{-/}$- littermates, despite showing a significant decrease in acute phase reactants [74]. Thus, currently there is more experimental evidence that argues in favor of a protective rather than detrimental role of IL6R signaling in atherosclerosis. Studies performed with gp130 loss and gain of function models are also far from conclusive. Specific gp130 hepatic deletion in Apoe $/$ mice significantly decreased APR reactants and atherosclerotic plaque formation. However, gp130 overexpression in Apoe $\%$ was associated with reduced (or no change in) atherosclerotic plaque formation despite increased production of APR reactants and macrophage infiltration [75].

On the other hand, the contribution of IL6-trans signaling to atherosclerosis has not been studied thoroughly. Based on the only experiment that has been reported so far, IL6 trans-signaling is considered as an important contributor to atherogenesis [76]. $\mathrm{Ldlr} /$ - mice treated with recombinant sgp130-Fc (to selectively block IL6 trans-signaling) showed significant reduction in the development of atherosclerosis, which was attributed to a decrease of EC activation and SMC migration. Nevertheless, results from that experiment may be biased due to the fact that the control group was injected with saline and did not receive a human control IgG to match the experimental group that received sgp-130Fc of human origin. Thus, further validation experiments are needed to better elucidate the contribution of IL6 trans-signalling to atherosclerosis.

Translational studies: IL6 is highly expressed in atherosclerotic plaques, but whether it exerts a pro- or anti-atherosclerotic role remains unclear, as both proand anti-inflammatory properties have been reported. For example, IL6 signaling pathway enhances vascular cell activation but also promotes SMC survival. It activates T cells and promotes their differentiation towards the Th17 subset, with either pro- or anti-atherogenic properties (see below). IL6 also promotes an antiinflammatory macrophage phenotype and may enhance the synthesis of IL1RN and the production of soluble TNF receptor.

Epidemiological studies in general found a significant association between high IL6/sIL6R levels and CV risk [77-80] without providing any causal explanation.

More recent Mendelian randomization studies tried to address the issue of casuality and focused on a SNP in the IL6R that was highly associated with increased circulating concentrations of IL6 and sIL6R [81,82] but reduced expression of mIL6R. Both studies found that the IL6R SNP rs2228145 (IL6R Asp158Ala) was not associated with lipid concentrations, blood pressure, adiposity, dysglycemia or smoking. Nevertheless, the 358Ala variant was associated with a significant decrease of CRP and fibrinogen levels, and reduced 
risk of CV disease. The data was interpreted as a proof that reduced IL6 signaling was responsible for the reduced risk of CVD. It is intriguing to note however that others have linked the same polymorphism to increased risk of asthma and interpreted their results as a proof-of-concept that increased (not decreased) IL6 signaling was responsible for the increased risk of asthma $[83,84]$. Thus, the same IL6R polymorphism is associated on one hand with increased risk of asthma, pushing investigators to propose IL6 blockade as a strategy to treat the disease, and on the other hand with reduced risk of CVD, leading investigators to support IL6 blockade as a promising strategy to reduce CVD risk. This testifies to our limited knowledge about the true impact of that polymorphism on IL6 signaling. Soluble Il6R is believed to act as an IL6 buffer system limiting IL6 signaling. However, as explained above, sIL6R binding to IL6 also activates IL6 transsignaling pathway in cells that only express gp130. Thus, it remains plausible that individuals with the 385Ala variant may show decreased classical activation due to reduced mIL6R, which perfectly explains the decrease in acute phase proteins, but may display increased (not decreased) trans-signaling due to increased IL6 and sIL6R levels. Another polymorphism in the human gp130 homologue, IL6 signal transducer was reported to be associated with CAD. However, the association was mostly limited to the ostium of the coronary arteries in very selected patient populations [85]. Thus, further studies are needed to elucidate the role of classical and trans-signaling of IL6 in the human setting.

\section{Clinical trials:}

Several antibodies were designed to inhibit the IL6 pathway and have been used in phase II and III clinical trials to study their efficacy in RA, and other autoimmune diseases and certain cancers. Tocilizumab is a monoclonal humanized antibody of the IgG1 class that was generated by grafting the complementarity determining regions of a mouse anti-human IL6R antibody onto human IgG1. It blocks IL6mediated signal transduction through inhibition of mIL6R and sIL6R. Its use to treat RA has been approved in more than 90 countries worldwide. Data regarding the safety of tocilizumab have been collected from RA patients and the overall safety profile is consistent across all global clinical studies. Patients with RA present increased risk of fatal CV accidents, but paradoxically they also present with lower cholesterol levels. Treatment with tocilizumab in RA patients has been associated with a significant improvement of the disease, but was associated with increased circulating levels of total cholesterol and triglycerides [86,87]. The results were corroborated in several trials. In the ADACTA (Adalimumab Acterma) phase IV clinical trial, monotherapy with tocilizumab was compared to adalimumab (anti-TNF monoclonal antibody) in MTX refractory RA patients. Tocilizumab treatment was associated with greater reduction in CRP and other anti-inflammatory composites compared to adalimumab, despite increasing circulating lipid levels [88]. Tocilizumab effect on lipid parameters is probably unrelated to direct blockade of IL6 signaling as it was not observed in individuals carrying the IL6R variant 358Ala [81,82]. It is also argued that while all lipoproteins are increased with tocilizumab, LDL/HDL, TC/HDL and ApoB/ApoA1 ratios, which predict $\mathrm{CV}$ risk more accurately than other lipid parameters, remain the same, suggesting little direct impact of lipoprotein changes on CV risk. Several phase IV clinical trials have tried to provide insight into this paradoxical effect on lipids studying not only quantitative but also qualitative lipoproteins changes in RA patients treated with tocilizumab. As an example, treatment with tocilizumab 
on top of MTX did not significantly increase pro-atherogenic small dense LDL, but significantly increased (non-atherogenic) small and medium HDL particles, in comparison to MTX alone. Paraoxonase 1 was increased, and HDL-associated serum amyloid A and SPLA 2 -IIa were decreased after tocilizumab, suggesting that IL6R blockade may promote an HDL translational change into a less inflammatory state [89]. However, circulating levels of HDL-cholesterol and sPLA2-IIa are only markers of $\mathrm{CV}$ risk and have both been invalidated as causal factors in human CAD (see below for $\mathrm{sPLA}_{2}$ ). In the double-blind phase of the five core studies of tocilizumab, a decreased number of MI were reported with all tocilizumab doses [90]. However, more evidence is needed regarding the impact of tocilizumab on CV events in patients with RA before starting trials to test the efficacy of tocilizumab in $\mathrm{CV}$ diseases outside the RA field.

\section{Lp-PLA2}

Pathophysiological pathway: Phospholipases $\mathrm{A}_{2}\left(\mathrm{PLA}_{2}\right)$ belongs to a superfamily of enzymes that hydrolyses glycerophospholipids at the position $s n-2$, producing non-esterified fatty acids (p.e. arachidonic acid and lysophospholipids). PLA 2 are classified as either cytosolic or extracellular, lipoprotein associated PLA 2 (Lp-PLA2) and secreted PLA 2 (SPLA $\left._{2}\right)$ belong to the latter group of enzymes.

Lp-PLA 2 is a $\mathrm{Ca}^{2+-i n d e p e n d e n t ~} 45 \mathrm{kDA}$ secreted protein that circulates in plasma associated with lipoproteins. In healthy individuals, it is typically associated to LDL and to a lesser extent to HDL and lipoprotein a (Lp-a) (extensively reviewed in [91]). It is widely secreted by immune cells involved in atherosclerosis such as macrophages, $\mathrm{T}$ lymphocytes and mast cells. It exhibits phospholipase and lipase activities. It was first discovered for its ability to hydrolyze platelet-activator factor factor (PAF) and so was called PAF-acetylhydrolase, but it also hydrolyzes oxPL. By cleaving an oxidized phosphatidylcholine component of the lipoprotein particle, it generates potent proinflammatory and proatherogenic mediators like oxidized non-esterified fatty acids, arachidonic acid and lysophosphatidylcholine (LysoPC). OxPLand fatty acids may promote atherosclerosis through a range of mechanisms (extensively reviewed in [91]). The effects of cyclooxygenases and lipoxygenases on arachidonic acid may generate proatherosclerotic mediators such as thromboxanes and leukotrienes. LysoPC increases endothelial activation, monocyte recruitment and differentiation into M1 pro-inflammatory macrophages. Experimental studies: Several studies found an atheroprotective role of Lp-PLA 2 in $А$ ров $\%$ mice and in a post-angioplasty restenosis model in rabbits [92,93]. Nevertheless, Lp-PLA 2 is bound to HDL in mice, while it is attached to LDL in humans. Thus, murine experimental studies were not considered to be very informative. In hypercholesterolemic minipigs however, a correlation was found between oxLDL, lysoPC and Lp-PLA2 levels resulting in accelerated atherosclerosis [94]. On the other hand, diabetic/ hypercholesterolemic swines treated with darapladib (a selective pharmacological inhibitor of Lp-PLA $_{2}$ presented a significant decrease of lysoPC in lesions, associated with significant, although modest, reduction of atherosclerotic plaque size and necrotic core area [95].

\section{Translational studies:}

Lp-PLA 2 was demonstrated to be highly up- regulated in macrophages located in the lipid core and fibrous cap of vulnerable and ruptured human coronary arteries, but not within stable lesions [96]. The reason for this may be due to the fact that pro-inflammatory macrophages M1 (more abundant in the necrotic core of 
unstable plaques) secrete much higher amounts of this enzyme than the antiinflammatory M2. Indeed, patients with a previous episode of CV event express higher Lp-PLA 2 and lysoPC than patients with no CV history, suggesting a potential role of Lp-PLA 2 in plaque composition and vulnerability.

Several epidemiological studies (reviewed in [91]) tried to elucidate the potential prognostic value of $\mathrm{Lp}-\mathrm{PLA} 2$ in CAD but reached opposite conclusions. A metaanalysis evaluating data from 36 prospective studies with a total sample size of 126,634 patients concluded to a modest association between Lp-PLA2 concentration, but not activity, with CAD [97]. However, another meta-analysis analyzing data from 79,036 individuals in 32 prospective studies found a significant correlation between Lp-PLA 2 mass or activity and CAD [98]. Several polymorphisms have been related to different levels of Lp-PLA 2 activity. However, inconsistent results were reached regarding their association with CAD. A missense polymorphism Val279Phe in PLA2G7 gene is present in approximately $30 \%$ of the Japanese population, and heterozygotes or homozygotes carriers of this polymorphism display reduced or no catalytic activity respectively; those individuals are not protected from CAD. A meta-analysis compiling information from 14 association studies focusing on 3 polymorphisms $A 379 \mathrm{~V}, V 279 \mathrm{~F}$ and $R 92 \mathrm{H}$, concluded to an association between $R 92 \mathrm{H}$ allele and increased $\mathrm{CV}$ risk, but that variant was not associated with significant changes of Lp-PLA 2 activity. The other $279 \mathrm{~F}$ and $379 \mathrm{~V}$ variants were associated with decreased Lp-PLA 2 activity but were not associated with CHD risk [99]. Finally, in a recent study, carriers of loss-offunction variant in PLA2G7 (rs140020965; Q287X) had almost 3-fold lower levels of Lp-PLA 2 activity but no difference in risk of incident CAD compared with noncarriers [100].

\section{Clinical trials}

Darapladib was developed as a potent and reversible oral inhibitor of Lp-PLA2.

Based on some epidemiologic studies supporting an association between Lp-PLA 2 and CV risk, several clinical trials were launched to assess the effect of darapladib on $\mathrm{CV}$ events in patients with stable or unstable CAD. After two encouraging phase II clinical trials [101,102], two phase III clinical trials were launched. In the STABILITY (Stabilization of Atherosclerosis Plaque by Darapladib Initiation of Therapy) trial, 15,828 patients with stable CAD were randomly assigned to darapladib $160 \mathrm{mg} /$ day or placebo (on top of optimal treatment) for a total of 3.7 years. Unfortunately, darapladib did not reduce the incidence of the primary endpoint, a composite of CV death, MI or stroke [103]. Some have argued that the negative result could be explained by the fact that those patients were already on statins, drugs with a very important impact on cholesterol levels (both groups presented LDL levels below $70 \mathrm{mg} / \mathrm{dL}$ ) and Lp-PLA 2 (it has been previously reported that statins reduce Lp-PLA 2 levels by $35 \%$ ). The second phase III clinical trial, SOLID-TIMI 52 (the Stabilization of Plaques Using Darapladib-Thrombolysis in MI 52 Trial) evaluated the effect of darapladib (160 mg/day) vs. placebo in 13,026 patients with ACS for an average period of 2.5 years. Again darapladib treatment did not improve the primary endpoint of major CV events [104]. Overall, the use of darapladib is not recommended for the treatment or prevention of CV events.

SPLA2

Pathophysiological pathway: sPLA2 are a group of enzymes with low molecular weight (from 14 to $19 \mathrm{kDa}$ ) and a $\mathrm{Ca}^{2+}$-dependent phospholipase activity. Various 
sPLA $_{2}$ may exhibit independent non-redundant roles. They are localized in different chromosomes, though 6 of them reside in the same gene cluster. Among them, the sPLA2-II/V cluster has been described in humans to be a candidate susceptibility locus. Both, SPLA2-II and V are increased by proinflammatory stimuli and are downregulated by anti-inflammatory cytokines. sPLA2-II accumulates in inflammatory fluids (p.e. synovial fluid in patients with RA) and is constitutively expressed in organs dealing with inflammatory responses like spleen, thymus, bone marrow, intestines, ovary and lung [105]. sPLA 2 -V is constitutively expressed in different tissues but mainly in the heart.

sPLA $_{2}$-II, III, V and X are able to hydrolyse phosphatidylcholine in LDL leading to the formation of unsaturated fatty acids and lysoPC. They also give rise to the formation of smaller and denser LDL and enhance foam cell formation, potentially exhibiting an important role in the initiation of atherosclerosis. Because sPLA $\mathrm{A}_{2}$-III, $\mathrm{V}$ and $\mathrm{X}$ are not detected in high concentrations in serum, they are believed to exert their actions on LDL accumulated in the intima. SPLA2-IIA is the predominant isoform in serum and the arterial wall, and despite having a modest LDL hydrolyzing activity, its high levels may somehow compensate for its low activity. sPLA $_{2}$ also exhibit non-enzymatic roles, through binding to M-type receptors on neutrophils, monocytes and macrophages, inducing pro-inflammatory cytokines and chemokine production.

Experimental evidence: $\mathrm{C} 57 \mathrm{Bl} 6$ mice have a natural null mutation in the $\mathrm{SPLA}_{2}$ IIA gene (Pla2g2a), thus several mouse lines overexpressing different human sPLA $_{2}$ have been developed. Transgenic Pla2g2a C57Bl6 mice presented bigger atherosclerotic lesions than their WT littermates after the consumption of a high fat diet [106]. The same results were obtained in $L d l r^{-/}$transplanted with BM from Pla2g2a Tg mice and macrophage-specific Pla2g2a Tg mice, thus confirming an atherogenic role of sPLA $_{2}$-IIA in mice [107].

Transplantation of $\mathrm{Ldlr} \%$ with BM from transgenic Pla2g5 gene promoted increased atherosclerotic plaques [108]; whereas mice transplanted with Pla2g5\% $\mathrm{BM}$ had reduced atherosclerotic lesion size and collagen deposition in comparison to their WT littermates [108]. Nevertheless, Apoe $/$ mice with deficiency in Pla2g5 did not show decreased atherosclerotic plaques despite lower collagen deposition. These controversial results were attributed to differential enrichment of Apoe $\%$ (compared to $\mathrm{Ldlr}^{-/}$)-derived LDL in sphingomyelin, which alters SPLA2-V hydrolytic activity.

sPLA2-X shows the most potent hydrolyzing activity toward PC, suggesting a proatherogenic role. However, Ldlr/- transplanted with BM from mouse group Xdeficient mice (Pla2g10\%) surprisingly had bigger atherosclerotic plaques. Also, overexpression of human PLA2G10 in murine bone marrow cells led to significant reduction of Th1 response and atherosclerotic plaque development, challenging the pro-atherogenic paradigm of sPLA2 activity, and suggesting that inhibition of total sPLA2 activity may lead to detrimental CV effects [109].

Varespladib (from Anthera Pharmaceuticals) is a drug that specifically inhibits sPLA2-IIA, $\mathrm{V}$ and $\mathrm{X}$ but does not act on sPLA2-III. Its protective role on atherosclerosis has been tested in 2 different studies using Apoe ${ }^{-/}$mice. Varespladib used alone significantly decreased atherosclerotic plaque formation and aneurysm development when compared to non-treated animals [110]. In the second study, varespladib was used in combination with a statin (pravastatin) at low doses; this combined effect decreased atherosclerosis to a bigger extent than 
each drug on its own, supporting a potential synergistic effect between these two drugs [111].

Translational studies: Several epidemiological studies tried to address the potential prognostic value of SPLA 2 in atherosclerosis. Elevated SPLA2-IIA levels have been associated with increased CV risk in several cohorts of patients with stable CAD [112-114]. The largest study that confirmed the prognosis value of $\mathrm{sPLA}_{2}$ in stable CAD patients was the PEACE study where elevated levels of sPLA 2 were significantly associated with the risk of CV disease, MI and stroke, even after multivariate adjustment including Lp-PLA 2 and CRP [115]. Disappointingly however, Mendelian randomization studies did not support a causal role for sPLA2 in CHD [116,117].

Clinical trials: Several clinical trials have been launched to study the security and efficacy of varespladib in CAD. PLASMA I (phospholipase levels and serological markers of atherosclerosis) was a phase II, randomized, double-blind and placebocontrolled, parallel-arm, dose-response clinical trial to evaluate the effect of 4 different doses of varespladib in 396 patients with stable CAD [118]. The aim was to study the effect of an 8-week treatment on sPLA2-IIA levels, oxLDL, hsCRP, LDL particle size, plasmatic arachidonic acid and leukotriene B4 levels. The authors reported a dose-dependent decrease in sPLA2-II (reaching up to $90 \%$ in treated vs. $5 \%$ in placebo) in patients treated with varespladib. Treatment also led to an $8 \%$ significant decrease of LDL levels in comparison to placebo. No significant changes were found in any other CV biomarker. PLASMA II was also a phase II, randomized, placebo-controlled study that was launched to study the effect of a daily single dose of varespladib (two different doses, 250 and $500 \mathrm{mg}$ ) in 197 patients with stable CAD, and reached the same conclusion as PLASMA I [119].

Another phase II clinical trial called FRANCIS (Fewer Recurrent Acute coronary events with Near-term Cardiovascular Inflammation Suppression) was designed to examine the impact of $500 \mathrm{mg}$ of varespladib or placebo in association with atorvastatin $80 \mathrm{mg}$ daily administered to patients within 96 hours of an ACS event and for 6 months. Varespladib treatment successfully reduced cholesterol, CRP and sPLA2-IIA levels [120]. These results led to a phase III clinical trial VISTA-16 that included more than 5,000 patients worldwide. Despite achieving lower cholesterol and CRP levels, patients treated with varespladib were not protected against the recurrence of $\mathrm{CV}$ events. The trial was stopped before completion due to increased incidence of MI in the varespladib group. Thus, varespladib may be harmful and is not a useful strategy to reduce adverse CV outcomes after ACS [121]. The results could have been predicted based on some experimental [109] and Mendelian randomization studies [116,117].

\section{Therapies targeting the adaptive $\mathrm{CD4}^{+} \mathrm{T}$ cell immune response}

The adaptive immune response is a specialized response. Innate immune cells, mainly macrophages and DC, act as antigen presenting cells (APC) and initiate the adaptive immune response. They drive the maturation and polarization of naïve $\mathrm{CD}^{+} \mathrm{T}$ cells through exposure of antigenic peptides on major histocompatibility complex class II molecule (MHCII), along with the engagement of co-stimulatory pathways. The antigenic epitopes that drive specific adaptive $\mathrm{T}$ cell immune responses in atherosclerosis are still to be characterized. However, an increasing body of evidence suggests a potential role for oxidized or native ApoB100-derived 
epitopes, but antigens derived from heat shock protein $60 / 65$ or other proteins may also play a role [122,123]. Activated T cells will differentiate into specific $\mathrm{Th}$ subtypes that secrete specific sets of cytokines and provide help to B cells favoring isotype switching, antigen-specific antibody production and induction of antibodyproducing plasma cells. The role of B cells in atherosclerosis has previously been published in this journal [124]. Therefore, we will focus here on the role of T cells. Primed naïve $\mathrm{T}$ cells can differentiate into at least 4 major $\mathrm{T}$ cell subtypes: Th1, Th2, Th17 and T regulatory (Tregs) cells. Polarization is induced by DC presenting antigens through MHCII to the TCR and interaction with co-stimulatory molecules like CD80, CD86, CD40 and OX40, binding to CD28, CD40L and OX40L on T cells. Additional soluble or membrane bound factors contribute to $\mathrm{T}$ cell polarization, e.g., IL12 and IL18 favor Th1 differentiation, CCL2, IL13 and IL6 may drive Th2, and TGF $\beta$, IL6 and IL1 $\beta$ promote Th17. Treg polarization requires MHCII-TCR binding along with low level co-stimulation through CD80/CD86 with CD28, CD80/CD86-CTLA4 and/or ICOS-ICOSL. All types of Th and Treg cells have been found in human atherosclerotic plaques, Th1 being the most prevalent. In general Th1 and its signature cytokine IFN $\gamma$ play an atherogenic role and their detrimental role in atherosclerosis has been extensively reviewed previously. Unfortunately, therapeutic tools that specifically target the Th1 response are not currently available. We will therefore focus on the other T cell subtypes.

\section{Th17:}

Pathophysiological pathway: Specific polarizing cytokines are required for Th17 differentiation. In mice, TGF $\beta$ represses Th1 and Th2 transcription factors, allowing IL6 to induce Th17 differentiation. IL6 activates STAT3 to up-regulate retinoic acid orphan receptors (ROR) $\alpha$ and $\gamma \mathrm{t}$, leading to the induction of the Th17 program. Also, in the absence of TGF $\beta$, IL6 and IL23 in conjunction with IL1 $\beta$ may cooperate to induce IL17 secretion and induce Th17 polarization (extensively reviewed in [125]). Upon activation, Th17 cells produce signature cytokines IL17, IL21 and IL22. However, Th17 do not represent a homogeneous subset, and can be reprogrammed into other $\mathrm{T}$ cell subsets depending on the cytokine environment. In fact, IL17 can be co-expressed with other cytokines like IFN $\gamma$, IL10 and IL4. Th17 may exhibit plasticity between Th1 cells and Tregs: a Th1/Th17 subset that coexpresses Tbet and ROR $\gamma \mathrm{t}$ has been found in some autoimmune settings, and a subset of ROR $\gamma \mathrm{t}^{+} \mathrm{T}$ cells that co-expresses Foxp3 $3^{+}$has also been identified. These recent findings involving Th17 plasticity may account for their controversial role in atherosclerosis.

The IL17 family includes 6 members, IL17A (known as IL17) to IL17F (known as IL25), that all bind to IL17 receptor (IL17R), which consists of 5 subunits (IL17RAIL17F). IL17RA is ubiquitously expressed throughout the body, resulting in a wide range of pleiotropic actions of IL17. IL17 enhances several pro-inflammatory signaling pathways including NF- $\mathrm{KB}$ and MAPK, which activate downstream target genes with important implications in atherosclerosis, mainly CXCL1 and 2 (involved in neutrophils and monocyte chemoattraction), IL6, IL1, MMPs and granulocyte MCSF.

Experimental evidence: The role of Th17 has widely been studied in mouse models of atherosclerosis, and has been shown to exert both pro and antiatherogenic effects (extensively reviewed in [125]). This is true for models using 
$I I 17 a \%$ mice, IL17A blocking antibodies, IL17A recombinant protein, or any other methodology used to down- or up-regulate IL17A signaling [126-133].

A recent experiment that had not been discussed in the previous review on the role of IL17 signaling in atherosclerosis[125], reported significant reduction of atherosclerotic plaque formation and increased stabilization after administration of a mouse anti-mouse IL17A antibody to 32 weeks-old Apoe $/$ mice fed a control chow diet [134]. However, we believe that the validity of this new study is compromised by the fact that the reported lipid profile (equivalent levels of total cholesterol and LDL-C at around $200 \mathrm{mg} / \mathrm{dl}$ ) did not correspond to an Apoe-/ mouse. Thus, our current interpretation of the bulk of experimental studies on the role of IL17 signaling in atherosclerosis is the following: Atherosclerotic mouse models are mostly driven by a Th1 response; if both Th1 and Th17 are increased, the outcome will be increased atherosclerosis; however, if IL17 induction leads to limitation of Th1 responses, the outcome will most likely be a protection against exacerbated atherosclerosis.

\section{Translational studies:}

Robust evidence shows that IL17 mediates adverse effects in RA, multiple sclerosis, systemic lupus erythematosus, and psoriasis [135] but less is known about its potential role in atherosclerosis. Increased numbers of $\mathrm{T}$ cells expressing IL17 were found in atherosclerotic plaques [134]. Recombinant IL17 increased monocyte cell adhesion to EC in vitro, promoted macrophage polarization into a pro-inflammatory phenotype, and increased MMP9 secretion by ex vivo plaque cultures On the other hand, work from our lab suggested an atheroprotective role for IL17. IL17 was expressed not only by T cells, but also in normal SMC from healthy human arteries. Intriguingly, IL17 expression was significantly decreased in medial SMC underlying atherosclerotic plaques, although its expression was still detected in plaque T cells. Recombinant IL17 reduced EC activation (VCAM1 expression) in culture, and high IL17 levels in human plaques were associated with a decrease in macrophage content and an increase of SMC and generally, with a more stable plaque [131]. Other investigators have subsequently corroborated the latter findings [136].

A very few epidemiological studies addressed the association between Th17 levels in blood and CV risk. One study found a significant increase of blood Th17 cells in subjects with ACS $(n=43)$ in comparison to patients with stable CAD or healthy controls $(n=20)$ [137]. In another study, increased blood levels of Th1-Th17 cells were found in patients with ACS [138]. The same authors reported that Th1-Th17 cultured cells from atherosclerotic coronary arteries produced a unique combination of IL17A and IFN $\gamma$ after polyclonal stimulation compared with T cells from healthy vessels, inducing pro-inflammatory responses in vascular SMC [139]. However, we have shown that circulating IL17A substantially reduces human mononuclear cell adhesion to TNF $\alpha$-activated human umbilical vein EC, which was associated with a significant reduction of sVCAM-1 expression, despite an increase of IL6 [140]. Moreover, in a large prospective and multicentric study enrolling 981 patients after an acute MI, low levels of circulating IL17 were associated with increased (not decreased) risk of all-cause death and recurrent MI at 2 years. IL17 was also negatively correlated with sVCAM1 levels, suggesting an important role of IL17 in EC activation. Thus, further translational studies must be performed before any definitive conclusion can be reached about the potential effect of Th17 T cell subtypes in atherosclerosis. 


\section{Clinical trials:}

Several neutralizing agents that inhibit IL17 signaling pathway have been developed due to their potential benefit in the treatment of autoimmune diseases. The first developed neutralizing antibody was ustekinumab, which targets the p40 subunit of the cytokines IL12 and IL23, and was approved in 2009 by the FDA to treat psoriasis. The biggest phase III Clinical Trial ACCEPT that demonstrated the efficacy of ustekinumab in psoriasis has already been reviewed in detail in this Journal [141].

Subsequently, at least two other IL17 neutralizing antibodies (secukinumab and ixekizumab) and one receptor blocking antibody (brodalumab) were developed and shown to be successful in Phase II Clinical Trials targeting autoimmune diseases like psoriasis. In fact, last year based on the results obtained in the CLEAR Phase III trial comparing ustekinumab and secukinumab, the latter was announced to be the first line-systemic treatment for moderate to severe plaque psoriasis. It is very intriguing however to note that in the placebo-controlled trials conducted to date, major CV events occurred only in the active arm, not in the placebo-treated group. As an example, in a recent study that addressed the effect of intravenous secukinumab (at a dose of $10 \mathrm{mg}$ per kilogram) at weeks 0,2 , and 4, followed by s.c. secukinumab at a dose of either $150 \mathrm{mg}$ or $75 \mathrm{mg}$ every 4 weeks, or placebo for a maximum of 24 weeks, 4 strokes and 2 MI were reported in the secukinumab group [142], and none in the placebo group [143]. During the placebo-controlled phases of the anti-p40 studies, 10 of 3179 patients receiving anti-p40 therapies experienced major adverse cardiovascular events compared with zero events in 1474 patients receiving placebo. By comparison, in the anti-TNF trials, only 1 of 3858 patients receiving anti-TNF therapy experienced a MACE compared with 1 of 1812 patients receiving placebo [143]. Thus, further experiments are needed to evaluate the cardiovascular safety of anti-p40 or IL17A/IL17R blockade in the long term. In the meanwhile, we recommend that patients treated with inhibitors of IL17A pathway are regularly checked and monitored to avoid unexpected CV events.

\section{Tregs:}

Pathophysiological pathway: Tregs are negative regulators of immune effector cells and are required to maintain immune homeostasis. They are essential in mediating peripheral tolerance, preventing autoimmune diseases, and suppressing inflammatory responses. There are two major classes of $\mathrm{CD} 4{ }^{+} \mathrm{CD} 25^{\mathrm{hi}}$ Tregs, naturally occurring Tregs (nTregs) and adaptive/induced Treg cells (iTreg) (reviewed in [144]). They depend on IL2 for development and survival. nTreg comprise a $5-10 \%$ of the total $C D 4^{+} \mathrm{T}$ cells in mice and humans, they mature within the thymus and they express Foxp3. Several important functions related to autoimmunity and atherosclerosis have been associated with Tregs. Fully mature nTreg cells exit the thymus, and migrate to secondary lymphoid organs (i.e. lymph nodes, spleen) [145]. Tregs also migrate to atherosclerotic arteries [146] and accumulate in tertiary lymphoid organs located in the adventitia of highly inflamed atherosclerotic vessels [147]. Tregs suppress autoimmune T cell proliferation and polarization, and inhibit polyclonal $\mathrm{T}$ cell activation, as well as the function of $\mathrm{B}$ cells, macrophages and DC. The mechanisms behind this immune suppressive role are multiple and may involve cell-to-cell contact, membrane-bound TGF $\beta$, IL10, CTLA4 or T effector cell deprivation of IL2. 
On the other hand, iTreg cells mature in the periphery from a CD4+CD25- T cell population. Upon stimulation within a favorable microenvironment (in the presence of TGF $\beta$, IL10 or IL4, but in the absence of IFN $\gamma$, IL1, IL6 or IL12) they may become $\mathrm{CD} 4{ }^{+} \mathrm{CD} 25^{+} \mathrm{T}$ cells with regulatory properties and a more or less stable Foxp3 expression. In the atherosclerosis setting they suppress $\mathrm{T}$ cell proliferation and activation, inhibit foam cell formation and redirect macrophage differentiation into the anti-inflammatory M2 phenotype.

Experimental evidence: $А р о e^{\%}$ mice have less Tregs in the spleen and demonstrate impaired immune suppressive properties compared to age-matched WT mice. In $L d l r^{-} /$mice, splenic Treg numbers increase after 4, 8 and 20 weeks on high fat diet. However, the numbers of circulating and lesional Treg peak at 4 weeks and decrease significantly at 8 and 20 weeks, concomitant with increased numbers of $\mathrm{CD}^{+}$effector T cells and increased lesion size over that period [146]. There is extensive evidence in mice implicating an anti-atheroslcerotic role for Treg cells. Significant aggravation of atherosclerosis is observed in different mouse models with depleted Tregs $[144,148,149]$. These include Treg deficiency due to deletion of CD80/CD86, CD28, ICOS, Foxp3-expressing T cells or Treg deficiency induced by the absence/depletion of tolerogenic DC or by injection of anti-CD25 blocking antibody. Also, depletion of Treg signature cytokines IL10 and TGF $\beta$ leads to exacerbated atherosclerosis, further supporting an atheroprotective role for Tregs.

On the other hand, adoptive transfer of $\mathrm{CD}^{+} \mathrm{CD} 25^{+}$or $\operatorname{Tr} 1$ cells, as well as expansion of Tregs after blockade of CCL17, significantly reduced atherosclerotic lesion development in Apoe-/ [150]. Strategies for vaccination or tolerization to enhance (antigen-specific) Tregs in atherosclerosis have been developed in mice, with mixed results [151-157]. This is mostly due to our limited knowledge about the causal antigenic epitopes in atherosclerosis [158] and the subtype of DC to be targeted in order to selectively induce a Treg response [159-164].

Administration of IL2/anti-IL2 mAb complexes, which leads to sustained increase of IL2 levels and a 10-fold increase of Tregs levels in blood, resulted in a significant reduction of atherosclerotic plaque formation and progression in $\mathrm{Ldll}^{-/}$mice [165]. Another experiment was designed to deliver IL2 directly into the atherosclerotic plaque. IL2 was coupled to L19, an antibody that recognizes the extradomain B of the extracellular matrix glycoprotein fibronectin (ED-B), which is differentially expressed in atherosclerotic plaques. Local IL2 administration significantly decreased the progression of pre-established atherosclerotic plaques due to the activation and proliferation of intra-plaque Treg cells in Apoe ${ }^{-/}$mice [166].

Translational studies: Treg are detected in much lower amounts in atherosclerotic plaques (1-5\% of all T cells) than in any other inflamed tissue $(25 \%$ of all $\mathrm{T}$ cells in eczema and psoriasis). This suggests that local $\mathrm{T}$ cell imbalance in the atherosclerotic plaque may play an important role in disease progression. The mechanisms behind Treg reduction in atherosclerotic tissues are poorly understood (reviewed in [144]). A small study performed in 32 patients with ACS found reduced blood levels and less activated Tregs in comparison to healthy subjects [167]. A series of small size epidemiological studies corroborated those results $[137,168,169]$. In a random sample from the prospective Malmö Diet and Cancer Study ( $n=700$ participants between 68-73 years old), the number of circulating Tregs was inversely correlated with the development of MI and 
coronary events at follow-up [170]. Treg levels have also been inversely associated with plaque instability [171].

Clinical trials: Adoptive Treg transfer limits the progression of CV diseases in mice, and has therefore been considered as a potential therapeutic strategy in humans though its development is being slow (extensively reviewed in [172]). Ex vivo expanded human Treg cells were effective in the prevention and treatment of graft-versus-host disease or type I diabetes mellitus $[173,174]$. But no data are available at present on the effects and safety of transferred Treg cells in patients with CV disease. Another strategy that could be applied to atherosclerosis would involve the isolation of autologous DCs, their subsequent loading with appropriate antigen(s) ex vivo (e.g., immunogenic epitopes of modified LDL), and their reinjection to the patient. However, an important challenge is to select the right antigens and to target the right DC subset (reviewed in [175]).

As explained above, IL2 is a major cytokine required for Treg generation and maintenance. Recombinant IL2 (aldesleukin) is currently available and approved for the treatment of renal cell carcinoma and metastatic melanoma. In those settings, IL2 treatment is not aimed at activation of Tregs but IL2 is administered at very high doses to activate anti-tumor T effector cell activity. Such high dose IL2 may be associated with severe CV adverse effects (e.g., vascular leak syndrome characterized by tachycardia, increased vascular permeability and hypotension) due increased $\mathrm{T}$ cell activation and the occurrence of a "cytokine storm". We propose to re-purpose aldesleukin for the treatment of CV diseases. Indeed, the effect of IL2 on Tregs is mediated by high-affinity IL2 receptors on Tregs. Beyond differences in receptor expression, Tregs also display exquisite sensitivity to IL2 signaling compared to T effector cells. This makes (ultra)-low dose IL2 (which will selectively activate Tregs) an interesting and potentially useful tool to readjust the homeostatic imbalance between Tregs and $\mathrm{T}$ effectors in cardiovascular diseases. In Phase II clinical trials, low-dose IL2 has been demonstrated to be safe and efficient in the treatment of several auto-immune mediated diseases, including hepatitis $\mathrm{C}$ virus-induced vasculitis or graft-versus-host disease, increasing Treg levels by at least 2 fold, without any detectable activation of effector T cells $[176,177]$. We are currently testing a similar approach to promote Tregs in coronary patients with the aim to reduce vascular inflammation and limit cardiovascular events.

\section{Th2:}

Pathophysiological pathway: IL4 is the key cytokine that drives Th2 differentiation. DC secreting IL6 or activated by TSLP to express OX40L promote CD4 naïve T cells polarization and differentiation into Th2. This leads to STAT6 upregulation and induction of GATA3, which activates the expression of signature cytokines IL4 and IL5, leading to inhibition of IFN $\gamma$ production (reviewed in [178]). Like other Th subsets, Th2 also exhibit plasticity. For example, TGF $\beta$ induces Th2 secretion of IL9 suggesting their conversion into Th9 cells. Due to their inhibition of Th1 polarization, an anticipated anti-atherosclerotic role was first hypothesized for Th2. However, recent data indicate that their role in atherosclerosis may depend on their cytokine profile.

Experimental evidence: The first observation that suggested an atheroprotective role for Th2 cells came from an experiment performed in Th2-biased $\mathrm{BALB} / \mathrm{c}$ mice, which were found to be resistant to atherosclerosis in comparison to 
Th1-biased and athero-susceptible C57Bl/6 mice [179]. Moreover BALB/c Stat6\%mice showed increased atherosclerotic plaque formation when compared to their WT littermates [180].

Nevertheless, studies targeting Il4 led to controversial results. A first publication showed decreased atherosclerotic plaque formation in $\mathrm{Ldll} /$ transplanted with BM from Il4\% mice compared to WT [181]. But two subsequent experiments did not corroborate the results using either Apoe $\% / I 14 \%$ or $\mathrm{Ldll} \% / \mathrm{Il} 4 \%$ dKO mice $[182,183]$. More recent data suggest that selective targeting of type I IL4 receptor (IL4R $\alpha$ and common $\gamma$ chain) may attenuate atherosclerosis in comparison with the targeting of the type 2 receptor (IL4R $\alpha$ and IL13R $\alpha 1$ ) [184]. Currently, two Th2-related cytokines have been shown to exert anti-atherosclerotic functions. IL5 induces athero-protective antibody secretion in natural B1 cells. Transplantation of $\mathrm{Il} \% \% \mathrm{BM}$ in $\mathrm{Ldlr} \%$ enhanced atherosclerotic plaque formation, accompanied by a decrease in natural IgM production from B1 cells. The same authors also demonstrated that immunization of $A p o e^{-/}$mice with MDA-modified LDL reduced atherosclerosis through up-regulation of IL5 secretion and a resultant increase in natural IgM antibodies against oxidized epitopes [185]. IL33-dependent atheroprotection has also been attributed to Th2-mediated IL5 production and stimulation of B1-dependent natural IgM production [186].

IL13 is another Th2 secreted anti-atherogenic cytokine. Administration of IL13 to $\mathrm{Ldl} / \%$ led to a significant decrease in atherosclerotic plaque formation and increased stability, in part through reduction of endothelial inflammation and an induction of a favorable alternative macrophage phenotype [187]. It is important to highlight though, that IL5 and IL13 are not specific to Th2 cells, and are also secreted by innate lymphoid cells 2 (ILC2), which may play significant roles in atherosclerosis.

Translational studies: Immunologically, a skewed Th1/Th2 balance due to enhancement of Th1 cells and suppression of Th2 has been associated with the pathogenesis of human atherosclerosis [123]. The protective role assigned to Th2 was initially related to the secretion of IL10, an anti-inflammatory cytokine with major protective role in atherosclerosis $[188,189]$.

IL4, however, has not been associated with protection from atherosclerosis in humans [190]. Recent epidemiological studies found higher levels of IL4 in plasma of subjects with CAD in comparison to healthy controls [191,192]. Interestingly, an association between CAD and variants near the IL5 gene locus was identified, suggesting a potential role of a Th2-related cytokine in the progression and development of CAD [193]. In this case, a putative atheroprotective effect has been initially suggested for IL5 due to the negative correlation between its plasma levels and carotid intima thickness [194]. A larger European prospective study concluded to a weak association between IL5 levels and CV risk in women, and no association in men [195]. Moreover, recent Mendelian randomization approaches could not support a role for IL5 levels in intima-media thickness [196], and suggested alternative mechanisms to explain the relationship between SNPs in IL5 gene locus and CV risk. Nevertheless, autoantibodies against IL5 were significantly associated with peripheral artery disease in a high-throughput screening of pooled serum [197].

Clinical trials: Neutralizing antibodies against IL5 have been developed to treat severe asthma (reviewed in [198]). Given the potential atheroprotective role of IL5, we believe that we should be cautious about possible detrimental 
cardiovascular effects that such anti-IL5 therapies may induce in patients with severe asthma, particular in patients at high baseline CV risk. Finally, it is interesting to note that low-dose IL2 therapy, which expands Tregs, has also been shown to promote IL5 production by ILC2 [199]. Those data favorably argue for the use of such a strategy (increasing Tregs and ILC2-derived IL5) to treat CV diseases.

\section{Conclusion}

It is might be disappointing to see that despite the large body of observational and mechanistic evidence that implicates immune responses in the development and complications of cardiovascular diseases, this knowledge has not been translated yet into benefit for the patient. There are several potential explanations and as discussed in the review, the failure of some trials could have been predicted on the basis of genetic Mendelian randomization studies. Another point to consider is that the various components of the immune system often play complex roles at different stages of disease development and progression and in different disease contexts, which may lead to different impact on disease outcomes. This is notwithstanding that the same cytokine or signaling pathway may differentially alter the disease process through induction of pro- or anti-inflammatory programs in different cell subtypes. Thus, the overall impact of cytokine signaling blockade on disease outcome is expected to be modest in the general population of patients with cardiovascular diseases. However, we believe that the therapeutic effect may be improved if we are able to stratify patients and assign selective therapies to appropriate patient populations, moving towards more personalized medicine.

Expert commentary: There is extensive evidence relating the activation of the immune system to the development and complications of atherosclerosis, and recent data in humans support a causal role for some immune-mediated pathways in disease development. Yet, we still do not know whether manipulation of the immune system will have direct impact on disease outcome. Here, we have reviewed and discussed the most relevant innate and adaptive immune pathways currently considered for targeting in this setting, at the exception of B celldependent responses, which have recently been reviewed in detail in the Journal [124]. We highlighted the extraordinary opportunity now offered to directly test the inflammatory hypothesis of atherosclerosis in the clinic using currently available therapeutics. However there are a few important points to keep in mind:

1. The role of a given immune-mediated pathway in atherosclerosis is often interpreted in a simplistic dichotomic way, and important subtleties are frequently dismissed. For example, IL1 $\alpha$ and IL1 $\beta$ signaling pathways are pro-atherogenic. However, little importance is attached to the potential undesirable effect of IL1 blockade on lipid metabolism or plaque remodeling. IL6 pathway is almost invariably considered as pro-atherogenic despite the fact that deficiency of Il6 may be associated with acceleration of atherosclerosis. A similar comment pertains to the IL17A pathway, both in mice and in humans. Thus, a more balanced interpretation of the experimental and translational data is needed, which may help address and identify in more details the appropriate settings where an immune pathway can be targeted with minimal risk.

2. Most experimental studies focus on the development of atherosclerosis. Intriguingly, it appears that a modulation of the inflammatory response is also 
critical to the regression of atherosclerotic lesions (reviewed in [200]). Thus, increased attention should be directed to the understanding of the mechanisms of progression versus regression of established atherosclerotic plaques, with the aim to identify selective modulators of atherosclerosis regression.

3. Negative results of some large phase III clinical trials could have been predicted by the results of some experimental or human genetic studies. This is for example the case for sPLA2 and Lp-PLA2 inhibitors where Mendelian randomization studies in humans were unable to detect any evidence of causal relationship between SPLA2 or Lp-PLA2 enzymes and cardiovascular diseases. Use of such genetic studies should be considered whenever possible before embarking on large phase III clinical trials.

4. However, GWAS data addressing the causal relationship between immunemediated pathways and cardiovascular diseases should be interpreted with more caution. For example, the presence of an IL6R SNP, which is associated with higher circulating levels of sIL6R and IL6 but lower expression of mIL6R, has been interpreted as leading to increased IL6 signaling in a GWAS study that reported on the association between genetic variants and the risk for asthma [83,84], but was considered as responsible for reduced IL6 signaling in other GWAS studies that reported on the association between IL6R genotype and coronary heart disease $[81,82]$ or abdominal aortic aneurysm [83]. This testifies to our ignorance of the true impact of that SNP on IL6 signaling, and to the urgent need for more studies to better understand the determinants and roles of classic versus trans IL6 signaling in disease development and complications.

\section{Five Year View:}

The next five years will certainly profoundly shape our understanding of the role of immune pathways in cardiovascular diseases, particularly in the clinical setting. Results of several ongoing clinical trials will be published, namely CANTOS and CIRT, and additional information will be available regarding the impact of IL6R blockade on cardiovascular risk. Several phase II and phase III trials will be initiated to further test the implication of selective immune pathways in CVD. For example, our lab will be testing low-dose IL2 therapy to limit vascular inflammation and coronary events in patients with acute coronary syndromes, and $\mathrm{B}$ cell depletion using CD20 mAb to reduce infarct size and improve left ventricular ejection fraction in patients with acute myocardial infarction. The discovery of new pathways involved in CVD will continue, and we expect interesting data to be available during the next 5 years on the mechanisms relating some genetic risk variants to CVD. Finally, identification of pro-atherogenic epitopes and a better understanding of antigen presentation and the role of selective dendritic cell subsets in modulating pro- and anti-atherogenic immunity will pave the way for specific manipulation of the immune system, through vaccination or tolerization, with the aim to achieve a cost-effective and sustained reduction in disease burden

\section{Key Issues:}

- Atherosclerosis is a chronic inflammatory disease where innate and adaptive immune responses play major roles at all stages of the disease.

- Several phase III clinical trials are currently testing the immunoinflammatory hypothesis of atherosclerosis, the most promising ones being 
CANTOS (anti-IL1 $\beta$ ) and CIRT (Methotrexate). However, failure of those trials should not detract from testing the validity of other immunemediated pathways to reduce CVD.

- IL6R pathway is causally related to coronary artery disease and abdominal aortic aneurysm. However, more experiments are needed to clarify the specific contributions of each of the classical and trans-signaling pathways of IL6 to disease development and complications.

- Studies are needed to evaluate the long-term cardiovascular safety of antip40 and IL17A/IL17R blockade in patients with immune-mediated diseases. Meanwhile, we believe that those therapies should be avoided in patients at high cardiovascular risk. A similar cautious note applies to patients treated with anti-IL5 blocking antibodies.

- Promoting Treg cells, either through administration of low-dose IL2 or antigen-specific activation, may hold promise in the treatment of patients with cardiovascular diseases.

Figure 1: Currently available clinically approved drugs that interfere with the $T$ cell response. Specific polarizing cytokines are required for naïve CD4+ $\mathrm{T}$ cells differentiation into various helper (Th1, Th2, Th17) and regulatory $\mathrm{T}$ cell (Treg) subsets. After stimulation Th cells secrete signature cytokines with different potential roles in atherosclerosis (protective or atherogenic). Several drugs have been developed to interfere with $\mathrm{T}$ helper and regulatory functions in clinical settings of immune-mediated diseases other than atherosclerosis. Some of these drugs are presented in the box in the bottom right corner of the Figure, and color-coded with their target molecule. The diagram shows that those available drugs may significantly impact atherosclerosis and cardiovascular risk either in a positive or a negative manner.

\section{References}

1. Weber A, Wasiliew P, Kracht M. Interleukin-1 (IL-1) pathway. Sci. Signal. [Internet]. 3(105), cm1 (2010). Available from: http://www.ncbi.nlm.nih.gov/pubmed/20086235.

2. Kobayashi Y, Yamamoto K, Saido T, Kawasaki H, Oppenheim JJ, Matsushima K. Identification of calcium-activated neutral protease as a processing enzyme of human interleukin 1 alpha. Proc. Natl. Acad. Sci. U. S. A. [Internet]. 87(14), 5548-52 (1990). Available from:

http://www.pubmedcentral.nih.gov/articlerender.fcgi?artid=54362\&tool=p mcentrez\&rendertype $=$ abstract.

3. Zheng Y, Humphry M, Maguire JJ, Bennett MR, Clarke MCH. Intracellular interleukin-1 receptor 2 binding prevents cleavage and activity of interleukin-1alpha, controlling necrosis-induced sterile inflammation. Immunity. 38(2), 285-295 (2013).

4. Freigang S, Ampenberger F, Weiss A, et al. Fatty acid-induced mitochondrial uncoupling elicits inflammasome-independent IL-1 $\alpha$ and sterile vascular inflammation in atherosclerosis. Nat. Immunol. [Internet]. 14(10), 1045-53 (2013). Available from: http://www.ncbi.nlm.nih.gov/pubmed/23995233.

5. Moon J-S, Lee S, Park M-A, et al. UCP2-induced fatty acid synthase promotes NLRP3 inflammasome activation during sepsis. J. Clin. Invest. [Internet]. 125(2), 665-80 (2015). Available from: 
http://www.pubmedcentral.nih.gov/articlerender.fcgi?artid=4319445\&tool $=$ pmcentrez\&rendertype $=$ abstract.

6. Gabay C, Lamacchia C, Palmer G. IL-1 pathways in inflammation and human diseases. Nat. Rev. Rheumatol. [Internet]. 6(4), 232-241 (2010). Available from: http://www.nature.com/doifinder/10.1038/nrrheum.2010.4.

7. Duewell P, Kono H, Rayner KJ, et al. NLRP3 inflammasomes are required for atherogenesis and activated by cholesterol crystals. Nature [Internet]. 464(7293), 1357-1361 (2010). Available from:

http://www.pubmedcentral.nih.gov/articlerender.fcgi?artid=2946640\&tool $=$ pmcentrez\&rendertype $=$ abstract.

8. Sheedy FJ, Grebe A, Rayner KJ, et al. CD36 coordinates NLRP3 inflammasome activation by facilitating intracellular nucleation of soluble ligands into particulate ligands in sterile inflammation. Nat. Immunol. [Internet]. 14(8), 812-20 (2013). Available from:

http://www.pubmedcentral.nih.gov/articlerender.fcgi?artid=3720827\&tool =pmcentrez\&rendertype=abstract.

9. Elhage R, Maret A, Pieraggi M-T, Thiers JC, Arnal JF, Bayard F. Differential Effects of Interleukin-1 Receptor Antagonist and Tumor Necrosis Factor Binding Protein on Fatty-Streak Formation in Apolipoprotein E Deficient Mice. Circulation [Internet]. 97(3), 242-244 (1998). Available from: http://circ.ahajournals.org.ezpprod1.hul.harvard.edu/content/97/3/242.long.

10. Devlin CM, Kuriakose G, Hirsch E, Tabas I. Genetic alterations of IL-1 receptor antagonist in mice affect plasma cholesterol level and foam cell lesion size. Proc. Natl. Acad. Sci. U. S. A. 99(9), 6280-6285 (2002).

11. Merhi-Soussi F, Kwak BR, Magne D, et al. Interleukin-1 plays a major role in vascular inflammation and atherosclerosis in male apolipoprotein Eknockout mice. Cardiovasc. Res. 66(3), 583-593 (2005).

12. Alexander MR, Moehle CW, Johnson JL, et al. Genetic inactivation of IL-1 signaling enhances atherosclerotic plaque instability and reduces outward vessel remodeling in advanced atherosclerosis in mice. J. Clin. Invest. 122(1), 70-79 (2012).

13. Isoda K, Sawada S, Ishigami N, et al. Lack of interleukin-1 receptor antagonist modulates plaque composition in apolipoprotein E-deficient mice. Arterioscler. Thromb. Vasc. Biol. 24(6), 1068-1073 (2004).

14. Kamari Y, Werman-Venkert R, Shaish A, et al. Differential role and tissue specificity of interleukin-1alpha gene expression in atherogenesis and lipid metabolism. Atherosclerosis [Internet]. 195(1), 31-8 (2007). Available from: http://www.sciencedirect.com/science/article/pii/S0021915006007003.

15. Bhaskar V, Yin J, Mirza AM, et al. Monoclonal antibodies targeting IL-1 beta reduce biomarkers of atherosclerosis in vitro and inhibit atherosclerotic plaque formation in Apolipoprotein E-deficient mice. Atherosclerosis [Internet]. 216(2), 313-320 (2011). Available from: http://dx.doi.org/10.1016/j.atherosclerosis.2011.02.026.

16. Libby P, Wyler DJ, Janicka MW, Dinarello C a. Differential effects of human interleukin-1 on growth of human fibroblasts and vascular smooth muscle cells. Arteriosclerosis [Internet]. 5(2), 186-91 (1985). Available from: http://www.ncbi.nlm.nih.gov/pubmed/3872118.

17. Bevilacqua MP, Pober JS, Wheeler ME, Cotran RS, Gimbrone M a. Interleukin 
1 acts on cultured human vascular endothelium to increase the adhesion of polymorphonuclear leukocytes, monocytes, and related leukocyte cell lines. J. Clin. Invest. [Internet]. 76(5), 2003-11 (1985). Available from: http://www.pubmedcentral.nih.gov/articlerender.fcgi?artid=424265\&tool= pmcentrez\&rendertype=abstract.

18. Montesano R. Leukocyte interleukins induce cultured endothelial cells to produce a highly organized, glycosaminoglycan-rich pericellular matrix. J. Cell Biol. [Internet]. 99(5), 1706-1715 (1984). Available from: http://jcb.rupress.org/cgi/content/long/99/5/1706.

19. Martin S, Maruta K, Burkart V, Gillis S, Kolb H. IL-1 and IFN-gamma increase vascular permeability. Immunology. 64(February), 301-305 (1988).

20. Wang a M, Doyle M V, Mark DF. Quantitation of mRNA by the polymerase chain reaction. Proc. Natl. Acad. Sci. U. S. A. 86(December), 9717-9721 (1989).

21. Galea J, Armstrong J, Gadsdon P, Holden H, Francis SE, Holt CM. Interleukin-1 beta in coronary arteries of patients with ischemic heart disease. Arterioscler. Thromb. Vasc. Biol. 16(8), 1000-1006 (1996).

22. Clarke MCH, Talib S, Figg NL, Bennett MR. Vascular smooth muscle cell apoptosis induces interleukin-1-directed inflammation: Effects of hyperlipidemia-mediated inhibition of phagocytosis. Circ. Res. 106(2), 363372 (2010).

23. Van Tassell BW, Raleigh JMV, Abbate A. Targeting Interleukin-1 in Heart Failure and Inflammatory Heart Disease. Curr. Heart Fail. Rep. 12(1), 33-41 (2015).

24. Ikonomidis I, Lekakis J, Revela I, Andreotti F, Nihoyannopoulos P. Increased circulating C-reactive protein and macrophage-colony stimulating factor are complementary predictors of long-term outcome in patients with chronic coronary artery disease. Eur. Heart J. 26(16), 1618-1624 (2005).

25. Saitoh T, Kishida H, Tsukada Y, et al. Clinical significance of increased plasma concentration of macrophage colony-stimulating factor in patients with angina pectoris. J. Am. Coll. Cardiol. [Internet]. 35(3), 655-665 (2000). Available from: http://linkinghub.elsevier.com/retrieve/pii/S0735109799005835.

26. Kilic T, Ural D, Ural E, et al. Relation between proinflammatory to antiinflammatory cytokine ratios and long-term prognosis in patients with nonST elevation acute coronary syndrome. Heart [Internet]. 92(8), 1041-6 (2006). Available from:

http://www.pubmedcentral.nih.gov/articlerender.fcgi?artid=1861097\&tool $=$ pmcentrez\&rendertype $=$ abstract.

27. Correia LC, Garcia G, Kalil F, et al. Prognostic Value of TIMI Score versus GRACE Score in ST-segment Elevation Myocardial Infarction. Arq Bras Cardiol [Internet]. 103(2), 98-106 (2014). Available from: http://www.ncbi.nlm.nih.gov/pubmed/25029471.

28. Tsimikas S, Duff GW, Berger PB, et al. Pro-inflammatory interleukin-1 genotypes potentiate the risk of coronary artery disease and cardiovascular events mediated by oxidized phospholipids and lipoprotein(a). J. Am. Coll. Cardiol. 63(17), 1724-1734 (2014).

29. Tarlow JK, Blakemore AI, Lennard A, et al. Polymorphism in human IL-1 receptor antagonist gene intron 2 is caused by variable numbers of an 86-bp 
tandem repeat. Hum. Genet. [Internet]. 91(4), 403-4 (1993). Available from: http://www.ncbi.nlm.nih.gov/pubmed/8500797.

30. Olofsson PS, Sheikine Y, Jatta K, et al. A functional interleukin-1 receptor antagonist polymorphism influences atherosclerosis development. The interleukin-1beta:interleukin-1 receptor antagonist balance in atherosclerosis. Circ. J. [Internet]. 73(8), 1531-6 (2009). Available from: http://www.ncbi.nlm.nih.gov/pubmed/19574724.

31. Francis SE, Camp NJ, Dewberry RM, et al. Interleukin-1 receptor antagonist gene polymorphism and coronary artery disease. Circulation. 99(7), 861866 (1999).

32. Vohnout B, Di Castelnuovo A, Trotta R, et al. Interleukin-1 gene cluster polymorphisms and risk of coronary artery disease. Haematologica [Internet]. 88(1), 54-60 (2003). Available from: http://www.embase.com/search/results?subaction=viewrecord\&from=exp ort\&id=L36168855 \nhttp://sfx.library.uu.nl/utrecht?sid=EMBASE\&issn=03 906078\&id=doi:\&atitle=Interleukin-

1+gene+cluster+polymorphisms+and+risk+of+coronary+artery+disease \&sti tle=Haematologica \&.

33. Freitag D, Butterworth AS, Willeit $\mathrm{P}$, et al. Cardiometabolic effects of genetic upregulation of the interleukin 1 receptor antagonist: A Mendelian randomisation analysis. Lancet Diabetes Endocrinol. 3(4), 243-253 (2015).

34. Dinarello CA, Simon A, van der Meer JWM. Treating inflammation by blocking interleukin-1 in a broad spectrum of diseases. Nat. Rev. Drug Discov. [Internet]. 11(8), 633-652 (2012). Available from: http://www.nature.com/doifinder/10.1038/nrd3800.

35. Morton AC, Rothman AMK, Greenwood JP, et al. The effect of interleukin-1 receptor antagonist therapy on markers of inflammation in non-ST elevation acute coronary syndromes: the MRC-ILA Heart Study. Eur. Heart J. [Internet]. , 377-384 (2014). Available from:

http://www.ncbi.nlm.nih.gov/pubmed/25079365.

36. Ridker PM. Closing the loop on inflammation and atherothrombosis: why perform the CIRT and CANTOS trials? Trans. Am. Clin. Climatol. Assoc. [Internet]. 124, 174-90 (2013). Available from: http://www.pubmedcentral.nih.gov/articlerender.fcgi?artid=3715939\&tool $=$ pmcentrez\&rendertype $=$ abstract.

37. Ridker PM, Howard CP, Walter V, et al. Effects of interleukin-1 inhibition with canakinumab on hemoglobin A1c, lipids, C-reactive protein, interleukin-6, and fibrinogen a phase IIb randomized, placebo-controlled trial. Circulation. 126(23), 2739-2748 (2012). *CANTOS is the largest clinical trial currently ongoing testing the anti-inflammatory theory of atherosclerosis, and more particularly the efficacy of IL1 $\beta$ blockade on clinical cardiovascular outcome in patients with coronary artery disease. A phase IIb showed that canakinumab significantly reduces inflammation without major effect on LDL- or HDL-cholesterol.

38. Ben-Chetrit E, Levy M. Colchicine: 1998 update. Semin. Arthritis Rheum. 28(1), 48-59 (1998).

39. Raju NC, Yi Q, Nidorf M, Fagel ND, Hiralal R, Eikelboom JW. Effect of colchicine compared with placebo on high sensitivity C-reactive protein in patients with acute coronary syndrome or acute stroke: A pilot randomized 
controlled trial. J. Thromb. Thrombolysis. 33(1), 88-94 (2012).

40. Martínez GJ, Robertson S, Barraclough J, et al. Colchicine Acutely Suppresses Local Cardiac Production of Inflammatory Cytokines in Patients With an Acute Coronary Syndrome. J. Am. Heart Assoc. [Internet]. 4(8), e002128 (2015). Available from: http://jaha.ahajournals.org/lookup/doi/10.1161/JAHA.115.002128.

41. Nidorf SM, Eikelboom JW, Budgeon C a., Thompson PL. Low-dose colchicine for secondary prevention of cardiovascular disease. J. Am. Coll. Cardiol. [Internet]. 61(4), 404-406 (2013). Available from: http://dx.doi.org/10.1016/j.jacc.2012.10.027.

42. Verma S, Eikelboom JW, Nidorf SM, et al. Colchicine in cardiac disease: a systematic review and meta-analysis of randomized controlled trials. $B M C$ Cardiovasc. Disord. [Internet]. 15, 96 (2015). Available from: http://www.pubmedcentral.nih.gov/articlerender.fcgi?artid=4553011\&tool $=$ pmcentrez\&rendertype $=$ abstract.

43. Cronstein BN. Low-dose methotrexate: a mainstay in the treatment of rheumatoid arthritis. Pharmacol. Rev. [Internet]. 57(2), 163-72 (2005). Available from: http://www.ncbi.nlm.nih.gov/pubmed/15914465.

44. Genestier L, Paillot R, Fournel S, Ferraro C, Miossec P, Revillard JP. Immunosuppressive properties of methotrexate: Apoptosis and clonal deletion of activated peripheral T cells. J. Clin. Invest. 102(2), 322-328 (1998).

45. Ortiz Z, Shea B, Suarez-Almazor ME, Moher D, Wells GA, Tugwell P. The efficacy of folic acid and folinic acid in reducing methotrexate gastrointestinal toxicity in rheumatoid arthritis. A metaanalysis of randomized controlled trials. J. Rheumatol. 25(1), 36-43 (1998).

46. Nesher G, Osborn TG, Moore TL. Effect of treatment with methotrexate, hydroxychloroquine, and prednisone on lymphocyte polyamine levels in rheumatoid arthritis: correlation with the clinical response and rheumatoid factor synthesis. Clin Exp Rheumatol. 15(4), 343-347 (1997).

47. Montesinos MC, Takedachi M, Thompson LF, Wilder TF, Fern??ndez P, Cronstein BN. The antiinflammatory mechanism of methotrexate depends on extracellular conversion of adenine nucleotides to adenosine by ecto5???-nucleotidase: Findings in a study of ecto-5???-nucleotidase genedeficient mice. Arthritis Rheum. 56(5), 1440-1445 (2007).

48. Roubille C, Richer V, Starnino T, et al. The effects of tumour necrosis factor inhibitors, methotrexate, non-steroidal anti-inflammatory drugs and corticosteroids on cardiovascular events in rheumatoid arthritis, psoriasis and psoriatic arthritis: a systematic review and meta-analysis. Ann. Rheum. Dis. 74(3), 480-9 (2015).

49. Bulgarelli A, Martins Dias AA, Caramelli B, Maranhão RC. Treatment with methotrexate inhibits atherogenesis in cholesterol-fed rabbits. J. Cardiovasc. Pharmacol. [Internet]. 59(4), 308-14 (2012). Available from: http://www.ncbi.nlm.nih.gov/pubmed/22113347.

50. Thornton CC, Al-Rashed F, Calay D, et al. Methotrexate-mediated activation of an AMPK-CREB-dependent pathway: a novel mechanism for vascular protection in chronic systemic inflammation. Ann. Rheum. Dis. [Internet]. , 110 (2015). Available from: http://ard.bmj.com/cgi/doi/10.1136/annrheumdis-2014-206305. 
51. Coomes E, Chan ESL, Reiss AB. Methotrexate in atherogenesis and cholesterol metabolism. Cholesterol [Internet]. 2011, 503028 (2011). Available from:

http://www.pubmedcentral.nih.gov/articlerender.fcgi?artid=3070167\&tool $=$ pmcentrez\&rendertype $=$ abstract.

52. Reiss AB, Cronstein BN. Regulation of foam cells by adenosine. Arterioscler. Thromb. Vasc. Biol. 32(4), 879-886 (2012).

53. Micha R, Imamura F, Wyler von Ballmoos M, et al. Systematic Review and Meta-Analysis of Methotrexate Use and Risk of Cardiovascular Disease. Am. J. Cardiol. 108, 1362-1370 (2011).

54. Choi HK, Hernán M a, Seeger JD, Robins JM, Wolfe F. Methotrexate and mortality in patients with rheumatoid arthritis: a prospective study. Lancet [Internet]. 359(9313), 1173-7 (2002). Available from: http://www.ncbi.nlm.nih.gov/pubmed/11955534.

55. Franklin J, Farragher TM, Lunt M, et al. Excess risk of hospital admission for cardiovascular disease within the first 7 years from onset of inflammatory polyarthritis. Ann. Rheum. Dis. [Internet]. 69(9), 1660-1664 (2010). Available from: http://www.ncbi.nlm.nih.gov/pubmed/20498206.

56. Westlake SL, Colebatch AN, Baird J, et al. The effect of methotrexate on cardiovascular disease in patients with rheumatoid arthritis: A systematic literature review. Rheumatology. 49(2), 295-307 (2010).

57. Hochberg MC, Johnston SS, John AK. The incidence and prevalence of extraarticular and systemic manifestations in a cohort of newly-diagnosed patients with rheumatoid arthritis between 1999 and 2006. Curr. Med. Res. Opin. [Internet]. 24(2), 469-80 (2008). Available from: http://www.ncbi.nlm.nih.gov/pubmed/18179735.

58. Prodanovich S, Prodanowich S, Ma F, et al. Methotrexate reduces incidence of vascular diseases in veterans with psoriasis or rheumatoid arthritis. J. Am. Acad. Dermatol. 52(2), 262-7 (2005).

59. Everett BM, Pradhan AD, Solomon DH, et al. Rationale and design of the Cardiovascular Inflammation Reduction Trial: a test of the inflammatory hypothesis of atherothrombosis. Am. Heart J. [Internet]. 166(2), 199207.e15 (2013). Available from:

http://www.pubmedcentral.nih.gov/articlerender.fcgi?artid=3888829\&tool $=$ pmcentrez\&rendertype $=$ abstract.

60. Scheller J, Chalaris A, Schmidt-Arras D, Rose-John S. The pro- and antiinflammatory properties of the cytokine interleukin-6. Biochim. Biophys. Acta - Mol. Cell Res. 1813(5), 878-888 (2011).

61. Kishimoto T. IL-6: From its discovery to clinical applications. Int. Immunol. 22(5), 347-352 (2010).

62. Heinrich PC, Castell J V, Andus T. Interleukin-6 and the acute phase response. Biochem. J. 265(3), 621-636 (1990).

63. Croker BA, Krebs DL, Zhang J-G, et al. SOCS3 negatively regulates IL-6 signaling in vivo. Nat. Immunol. 4(6), 540-545 (2003).

64. Yasukawa $\mathrm{H}$, Ohishi M, Mori $\mathrm{H}$, et al. IL-6 induces an anti-inflammatory response in the absence of SOCS3 in macrophages. Nat. Immunol. 4(6), 551556 (2003).

65. Mauer J, Chaurasia B, Goldau J, et al. Signaling by IL-6 promotes alternative activation of macrophages to limit endotoxemia and obesity-associated 
resistance to insulin. Nat. Immunol. [Internet]. 15(5), 423-30 (2014).

Available from: http://www.ncbi.nlm.nih.gov/pubmed/24681566.

66. Rose-John S. Il-6 trans-signaling via the soluble IL-6 receptor: Importance for the proinflammatory activities of IL-6. Int. J. Biol. Sci. 8(9), 1237-1247 (2012).

67. Jones SA, Scheller J, Rose-John S. Therapeutic strategies for the clinical blockade of IL-6/gp130 signaling. J. Clin. Invest. 121(9), 3375-3383 (2011).

68. Diamant M, Rieneck K, Mechti N, et al. Cloning and expression of an alternatively spliced mRNA encoding a soluble form of the human interleukin-6 signal transducer gp130. FEBS Lett. 412(2), 379-384 (1997).

69. Jones GW, McLoughlin RM, Hammond VJ, et al. Loss of $\{$ CD4+ $\}$ T cell $\{$ IL-6R $\}$ expression during inflammation underlines a role for $\{\mathrm{IL}-6\}$ trans signaling in the local maintenance of Th17 cells. J. Immunol. \{(Baltimore, $\}$ Md. 1950) [Internet]. , 2130-2139 (2010). Available from: http://dx.doi.org/10.4049/jimmunol.0901528.

70. Keidar S, Heinrich R, Kaplan M, Hayek T, Aviram M. Angiotensin II Administration to Atherosclerotic Mice Increases Macrophage Uptake of Oxidized LDL: A Possible Role for Interleukin-6. Arterioscler. Thromb. Vasc. Biol. [Internet]. 21(9), 1464-1469 (2001). Available from: http://atvb.ahajournals.org/content/21/9/1464.long.

71. Huber SA, Sakkinen P, Conze D, Hardin N, Tracy R. Interleukin-6 Exacerbates Early Atherosclerosis in Mice. Arter. Thromb Vasc Biol [Internet]. 19, 23642367 (1999). Available from:

http://atvb.ahajournals.org/content/19/10/2364\nhttp://atvb.ahajournals .org//subscriptions/\nhttp://atvb.ahajournals.org/.

72. Elhage $\mathrm{R}, \mathrm{Clamens} \mathrm{S}$, Besnard $\mathrm{S}$, et al. Involvement of interleukin-6 in atherosclerosis but not in the prevention of fatty streak formation by 17 beta-estradiol in apolipoprotein E-deficient mice. Atherosclerosis [Internet]. 156(2), 315-320 (2001). Available from:

http://www.ncbi.nlm.nih.gov/entrez/query.fcgi?cmd=Retrieve\&db=PubMe d\&dopt=Citation\&list_uids=11395027.

73. Van Lenten BJ, Wagner AC, Navab M, Fogelman AM. Oxidized phospholipids induce changes in hepatic paraoxonase and apoJ but not monocyte chemoattractant protein-1 via interleukin-6. J. Biol. Chem. 276(3), 19231929 (2001).

74. Song L, Schindler C. IL-6 and the acute phase response in murine atherosclerosis. Atherosclerosis. 177(1), 43-51 (2004).

75. Jones GW, McLeod L, Kennedy CL, Bozinovski S, Najdovska M, Jenkins BJ. Imbalanced gp130 signalling in ApoE-deficient mice protects against atherosclerosis. Atherosclerosis. 238(2), 321-328 (2015).

76. Schuett H, Oestreich R, Waetzig GH, et al. Transsignaling of interleukin-6 crucially contributes to atherosclerosis in mice. Arterioscler. Thromb. Vasc. Biol. 32(2), 281-290 (2012).

77. Ridker PM, Rifai N, Stampfer MJ, Hennekens CH. Plasma concentration of interleukin- 6 and the risk of future myocardial infarction among apparently healthy men. Circulation [Internet]. 101(15), 1767-72 (2000). Available from: http://www.ncbi.nlm.nih.gov/pubmed/10769275.

78. Lindmark E, Diderholm E, Wallentin L, Siegbahn A. Relationship between interleukin 6 and mortality in patients with unstable coronary artery 
disease: effects of an early invasive or noninvasive strategy. JAMA [Internet]. 286(17), 2107-13 (2001). Available from: http://jama.amaassn.org/cgi/doi/10.1001/jama.286.17.2107\nhttp://www.ncbi.nlm.nih.go $\mathrm{v} /$ pubmed/11694151.

79. Luc G, Bard JM, Juhan-Vague I, et al. C-reactive protein, interleukin-6, and fibrinogen as predictors of coronary heart disease: The PRIME study. Arterioscler. Thromb. Vasc. Biol. 23(7), 1255-1261 (2003).

80. Fan Z-X, Hua Q, Li Y-P, Liu R-K, Yang Z. Interleukin-6, but Not Soluble Adhesion Molecules, Predicts a Subsequent Mortality from Cardiovascular Disease in Patients with Acute ST-Segment Elevation Myocardial Infarction. Cell Biochem. Biophys. 61(2), 443-448 (2011).

81. Sarwar N, Butterworth AS. Interleukin- 6 receptor pathways in coronary heart disease: A collaborative meta-analysis of 82 studies. Lancet. 379(9822), 1205-1213 (2012).*

82. Hingorani AD, Casas JP. The interleukin- 6 receptor as a target for prevention of coronary heart disease: a mendelian randomisation analysis. Lancet [Internet]. 379(9822), 1214-24 (2012). Available from: http://www.pubmedcentral.nih.gov/articlerender.fcgi?artid=3316968\&tool =pmcentrez\&rendertype=abstract $\backslash$ nhttp://www.sciencedirect.com/science /article/pii/S014067361260110X. *References 81 and 82 highlight the importance of performing large Mendelian randomization trials to identify causal variants/genes involved in cardiovascular diseases. It should be acknowledged, however, that those studies do not tell much about the differential roles of membrane versus trans IL6 signaling.

83. Ferreira RC, Freitag DF, Cutler AJ, et al. Functional IL6R 358Ala Allele Impairs Classical IL-6 Receptor Signaling and Influences Risk of Diverse Inflammatory Diseases. PLoS Genet. 9(4) (2013).

84. Ferreira MAR, Matheson MC, Duffy DL, et al. Identification of IL6R and chromosome 11q13.5 as risk loci for asthma. Lancet. 378(9795), 1006-1014 (2011).

85. Luchtefeld M, Schunkert H, Stoll M, et al. Signal transducer of inflammation gp130 modulates atherosclerosis in mice and man. J. Exp. Med. [Internet]. 204(8), 1935-44 (2007). Available from:

http://www.pubmedcentral.nih.gov/articlerender.fcgi?artid=2118681\&tool $=$ pmcentrez\&rendertype $=$ abstract .

86. Jones G. The AMBITION trial: tocilizumab monotherapy for rheumatoid arthritis. Expert Rev. Clin. Immunol. 6, 189-195 (2010).

87. Emery P, Keystone E, Tony HP, et al. IL-6 receptor inhibition with tocilizumab improves treatment outcomes in patients with rheumatoid arthritis refractory to anti-tumour necrosis factor biologicals: results from a 24-week multicentre randomised placebo-controlled trial. Ann. Rheum. Dis. [Internet]. 67(11), 1516-23 (2008). Available from: http://ard.bmj.com/content/67/11/1516.long.

88. Gabay C, Emery P, Van Vollenhoven R, et al. Tocilizumab monotherapy versus adalimumab monotherapy for treatment of rheumatoid arthritis (ADACTA): A randomised, double-blind, controlled phase 4 trial. Lancet. 381(9877), 1541-1550 (2013).

89. McInnes IB, Thompson L, Giles JT, et al. Effect of interleukin-6 receptor blockade on surrogates of vascular risk in rheumatoid arthritis: MEASURE, a 
randomised, placebo-controlled study. Ann. Rheum. Dis. [Internet]. , 1-9 (2013). Available from: http://www.ncbi.nlm.nih.gov/pubmed/24368514.

90. Schiff MH, Kremer JM, Jahreis A, Vernon E, Isaacs JD, van Vollenhoven RF. Integrated safety in tocilizumab clinical trials. Arthritis Res. Ther. [Internet]. 13(5), R141 (2011). Available from: http://arthritisresearch.com/content/13/5/R141.

91. Mallat Z, Lambeau G, Tedgui A. Lipoprotein-associated and secreted phospholipases A2 in cardiovascular disease: Roles as biological effectors and biomarkers. Circulation. 122(21), 2183-2200 (2010).

92. Theilmeier G, De Geest B, Van Veldhoven PP, et al. HDL-associated PAF-AH reduces endothelial adhesiveness in apoE-/- mice. FASEB J. [Internet]. 14(13), 2032-9 (2000). Available from: http://www.ncbi.nlm.nih.gov/pubmed/11023987.

93. Hiltunen MO, Laitinen M, Turunen MP, et al. Intravascular adenovirusmediated VEGF-C gene transfer reduces neointima formation in balloondenuded rabbit aorta. Circulation. 102(18), 2262-2268 (2000).

94. De Keyzer D, Karabina SA, Wei W, et al. Increased PAFAH and oxidized lipids are associated with inflammation and atherosclerosis in hypercholesterolemic pigs. Arterioscler. Thromb. Vasc. Biol. 29(12), 20412046 (2009).

95. Wilensky RL, Shi Y, Mohler ER, et al. Inhibition of lipoprotein-associated phospholipase A2 reduces complex coronary atherosclerotic plaque development. Nat. Med. 14(10), 1059-1066 (2008).

96. Kolodgie FD, Burke AP, Skorija KS, et al. Lipoprotein-associated phospholipase A2 protein expression in the natural progression of human coronary atherosclerosis. Arterioscler. Thromb. Vasc. Biol. 26(11), 25232529 (2006).

97. Emerging Risk Factors C, Erqou S, Kaptoge S, et al. Lipoprotein(a) concentration and the risk of coronary heart disease, stroke, and nonvascular mortality. JAMA [Internet]. 302(4), 412-423 (2009). Available from: http://www.ncbi.nlm.nih.gov/pubmed/19622820.

98. Lp PLASC, Thompson A, Gao P, et al. Lipoprotein-associated phospholipase $\mathrm{A}(2)$ and risk of coronary disease, stroke, and mortality: collaborative analysis of 32 prospective studies. Lancet [Internet]. 375, 1536-44 ST Lipoprotein-associated phospholipase (2010). Available from: http://ovidsp.ovid.com/ovidweb.cgi?T=JS\&CSC=Y\&NEWS=N\&PAGE=fulltext $\& \mathrm{D}=$ medl $\& \mathrm{AN}=20435228$.

99. Wang Q, Hao Y, Mo X, et al. PLA2G7 gene polymorphisms and coronary heart disease risk: A meta-analysis. Thromb. Res. 126(6), 498-503 (2010).

100. Polfus LM, Gibbs RA, Boerwinkle E. Coronary heart disease and genetic variants with low phospholipase A2 activity. N. Engl. J. Med. 372(3), 295296 (2015).

101. Mohler ER, Ballantyne CM, Davidson MH, et al. The effect of darapladib on plasma lipoprotein-associated phospholipase A2 activity and cardiovascular biomarkers in patients with stable coronary heart disease or coronary heart disease risk equivalent: the results of a multicenter, randomized, double-bl. J. Am. Coll. Cardiol. [Internet]. 51(17), 1632-41 (2008). Available from: http://www.sciencedirect.com/science/article/pii/S073510970800569X.

102. Serruys PW, Garc??a-Garc??a HM, Buszman P, et al. Effects of the direct 
lipoprotein-associated phospholipase A2 inhibitor darapladib on human coronary atherosclerotic plaque. Circulation. 118(11), 1172-1182 (2008).

103. White HD. Darapladib for Preventing Ischemic Events in Stable Coronary Heart Disease. N. Engl. J. Med. [Internet]. , 140330050005008 (2014). Available from: http://www.ncbi.nlm.nih.gov/pubmed/24678955.**

104. O'Donoghue ML, Braunwald E, White HD, et al. Effect of darapladib on major coronary events after an acute coronary syndrome: the SOLID-TIMI 52 randomized clinical trial. JAMA [Internet]. 312(10), 1006-15 (2014). Available from: http://jama.jamanetwork.com/article.aspx?articleid=1900827. ${ }^{* *}$ Reference 103 and 104 demonstrate the futility of Lp-PLA2 inhibition in the setting of coronary artery disease.

105. Niessen H. Type II secretory phospholipase A2 in cardiovascular disease: a mediator in atherosclerosis and ischemic damage to cardiomyocytes? Cardiovasc. Res. [Internet]. 60(1), 68-77 (2003). Available from: http://www.ncbi.nlm.nih.gov/pubmed?term=Type II secretory phospholipase A2 in cardiovascular disease: a mediator in atherosclerosis and ischemic damage to cardiomyocytes?

106. Tietge UJF, Maugeais C, Cain W, et al. Overexpression of secretory phospholipase A2 causes rapid catabolism and altered tissue uptake of high density lipoprotein cholesteryl ester and apolipoprotein A-I. J. Biol. Chem. 275(14), 10077-10084 (2000).

107. Webb NR, Bostrom MA, Szilvassy SJ, Van der Westhuyzen DR, Daugherty A, De Beer FC. Macrophage-expressed group IIA secretory phospholipase A2 increases atherosclerotic lesion formation in LDL receptor-deficient mice. Arterioscler. Thromb. Vasc. Biol. 23(2), 263-268 (2003).

108. Bostrom MA, Boyanovsky BB, Jordan CT, et al. Group V secretory phospholipase A2 promotes atherosclerosis: Evidence from genetically altered mice. Arterioscler. Thromb. Vasc. Biol. 27(3), 600-606 (2007).

109. Ait-Oufella H, Herbin O, Lahoute C, et al. Group X secreted phospholipase a2 limits the development of atherosclerosis in LDL receptor-null mice. Arterioscler. Thromb. Vasc. Biol. 33(3), 466-473 (2013).

110. Fraser H, Hislop C, Christie RM, et al. Varespladib (A-002), a secretory phospholipase A2 inhibitor, reduces atherosclerosis and aneurysm formation in ApoE-/- mice. J. Cardiovasc. Pharmacol. [Internet]. 53(1), 60-5 (2009). Available from: http://www.ncbi.nlm.nih.gov/pubmed/19129734.

111. Shaposhnik Z, Wang X, Trias J, Fraser H, Lusis AJ. The synergistic inhibition of atherogenesis in apoE-/- mice between pravastatin and the SPLA2 inhibitor varespladib (A-002). J. Lipid Res. [Internet]. 50(4), 623-9 (2009). Available from: http://www.pubmedcentral.nih.gov/articlerender.fcgi?artid=2656655\&tool =pmcentrez\&rendertype $=$ abstract.

112. Kugiyama K, Ota Y, Takazoe K, et al. Circulating levels of secretory type II phospholipase $\mathrm{A}(2)$ predict coronary events in patients with coronary artery disease. Circulation. 100(12), 1280-1284 (1999).

113. Liu P-Y, Li Y-H, Tsai W-C, et al. Prognostic value and the changes of plasma levels of secretory type II phospholipase A2 in patients with coronary artery disease undergoing percutaneous coronary intervention. Eur. Heart J. 24(20), 1824-1832 (2003). 
114. Koenig W, Twardella D, Brenner H, Rothenbacher D. Lipoprotein-associated phospholipase A2 predicts future cardiovascular events in patients with coronary heart disease independently of traditional risk factors, markers of inflammation, renal function, and hemodynamic stress. Arterioscler. Thromb. Vasc. Biol. 26(7), 1586-1593 (2006).

115. Sabatine MS, Morrow DA, O’Donoghue M, et al. Prognostic utility of lipoprotein-associated phospholipase A2 for cardiovascular outcomes in patients with stable coronary artery disease. Arterioscler. Thromb. Vasc. Biol. 27(11), 2463-2469 (2007).

116. Holmes M V, Exeter HJ, Folkersen L, et al. Novel genetic approach to investigate the role of plasma secretory phospholipase A2 (sPLA2)-V isoenzyme in coronary heart disease: modified Mendelian randomization analysis using PLA2G5 expression levels. Circ. Cardiovasc. Genet. [Internet]. 7(2), 144-50 (2014). Available from:

http://www.pubmedcentral.nih.gov/articlerender.fcgi?artid=4212409\&tool $=$ pmcentrez\&rendertype $=$ abstract.

117. Guardiola M, Exeter HJ, Perret C, et al. PLA2G10 Gene Variants, sPLA2 Activity, and Coronary Heart Disease Risk. Circ. Cardiovasc. Genet. 8(2), 356362 (2015).

118. Rosenson RS, Hislop C, McConnell D, et al. Effects of 1-H-indole-3glyoxamide (A-002) on concentration of secretory phospholipase A2 (PLASMA study): a phase II double-blind, randomised, placebo-controlled trial. Lancet (London, England). 373(9664), 649-658 (2009).

119. Rosenson RS, Elliott M, Stasiv Y, Hislop C. Randomized trial of an inhibitor of secretory phospholipase A2 on atherogenic lipoprotein subclasses in statintreated patients with coronary heart disease. Eur. Heart J. 32(8), 999-1005 (2011).

120. Rosenson RS, Hislop C, Elliott M, Stasiv Y, Goulder M, Waters D. Effects of varespladib methyl on biomarkers and major cardiovascular events in acute coronary syndrome patients. J. Am. Coll. Cardiol. 56(14), 1079-1088 (2010).

121. Nicholls SJ, Kastelein JJP, Schwartz GG, et al. Varespladib and cardiovascular events in patients with an acute coronary syndrome: the VISTA-16 randomized clinical trial. JAMA [Internet]. 311(3), 252-62 (2014). Available from: http://www.ncbi.nlm.nih.gov/pubmed/24247616. * This paper demonstrates the futility of sPLA2 inhibition in patients with acute coronary syndromes. Concomitant Mendelian randomization studies could not support a causal role for sPLA2 type IIA in coronary artery disease (see Ref 116 and 117).

122. Tse K, Tse H, Sidney J, Sette A, Ley K. T cells in atherosclerosis. Int Immunol [Internet]. 25(11), 615-622 (2013). Available from:

http://www.ncbi.nlm.nih.gov/pubmed/24154816\nhttp://intimm.oxfordjo urnals.org/content/25/11/615.full.pdf.

123. Mallat $\mathrm{Z}$, Taleb $\mathrm{S}$, Ait-Oufella $\mathrm{H}$, Tedgui A. The role of adaptive $\mathrm{T}$ cell immunity in atherosclerosis. J Lipid Res [Internet]. 50 Suppl, S364-9 (2009). Available from:

http://www.ncbi.nlm.nih.gov/entrez/query.fcgi?cmd=Retrieve \&db=PubMe $\mathrm{d} \&$ dopt=Citation\&list_uids $=19050311$.

124. Morris-Rosenfeld S, Lipinski MJ, McNamara CA. Understanding the role of B cells in atherosclerosis: potential clinical implications. Expert Rev. Clin. 
Immunol. [Internet]. 10(1), 77-89 (2014). Available from:

http://www.pubmedcentral.nih.gov/articlerender.fcgi?artid=4358742\&tool $=$ pmcentrez\&rendertype $=$ abstract.

125. Taleb S, Tedgui A, Mallat Z. IL-17 and Th17 cells in atherosclerosis: Subtle and contextual roles. Arterioscler. Thromb. Vasc. Biol. 35(2), 258-264 (2015).

126. Chen S, Shimada K, Zhang W, Huang G, Crother TR, Arditi M. IL-17A is proatherogenic in high-fat diet-induced and Chlamydia pneumoniae infection-accelerated atherosclerosis in mice. J Immunol [Internet]. 185(9), 5619-5627 (2010). Available from:

http://www.ncbi.nlm.nih.gov/pubmed/20935201\nhttp://www.jimmunol. org/content/185/9/5619.full.pdf.

127. Erbel C, Chen L, Bea F, et al. Inhibition of IL-17A attenuates atherosclerotic lesion development in apoE-deficient mice. J. Immunol. 183(12), 8167-8175 (2009).

128. Cheng X, Taleb S, Wang J, et al. Inhibition of IL-17A in atherosclerosis. Atherosclerosis. 215(2), 471-474 (2011).

129. Smith E, Prasad K-MR, Butcher M, et al. Blockade of interleukin-17A results in reduced atherosclerosis in apolipoprotein E-deficient mice. Circulation. 121(15), 1746-1755 (2010).

130. van Es T, van Puijvelde GHM, Ramos $\mathrm{OH}$, et al. Attenuated atherosclerosis upon IL-17R signaling disruption in LDLr deficient mice. Biochem. Biophys. Res. Commun. 388(2), 261-265 (2009).

131. Taleb S, Romain M, Ramkhelawon B, et al. Loss of SOCS3 expression in T cells reveals a regulatory role for interleukin-17 in atherosclerosis. J Exp Med [Internet]. 206(10), 2067-2077 (2009). Available from:

http://www.ncbi.nlm.nih.gov/entrez/query.fcgi?cmd=Retrieve\&db=PubMe $\mathrm{d} \&$ dopt=Citation\&list_uids=19737863.

132. Ait-Oufella $\mathrm{H}$, Herbin $\mathrm{O}$, Bouaziz J-D, et al. B cell depletion reduces the development of atherosclerosis in mice. J. Exp. Med. 207(8), 1579-1587 (2010).

133. Danzaki K, Matsui $Y$, Ikesue $M$, et al. Interleukin-17A deficiency accelerates unstable atherosclerotic plaque formation in apolipoprotein e-deficient mice. Arterioscler. Thromb. Vasc. Biol. 32(2), 273-280 (2012).

134. Erbel C, Akhavanpoor M, Okuyucu D, et al. IL-17A Influences Essential Functions of the Monocyte/Macrophage Lineage and Is Involved in Advanced Murine and Human Atherosclerosis. J. Immunol. [Internet]. 193(9), 4344-4355 (2014). Available from: http://www.jimmunol.org/cgi/doi/10.4049/jimmunol.1400181.

135. Ghoreschi K, Laurence A, Yang XP, Hirahara K, O’Shea JJ. T helper 17 cell heterogeneity and pathogenicity in autoimmune disease. Trends Immunol. 32(9), 395-401 (2011).

136. Gisterå A, Robertson A-KL, Andersson J, et al. Transforming growth factor- $\beta$ signaling in T cells promotes stabilization of atherosclerotic plaques through an interleukin-17-dependent pathway. Sci. Transl. Med. [Internet]. 5(196), 196ra100 (2013). Available from: http://www.ncbi.nlm.nih.gov/pubmed/23903754.

137. Cheng X, Yu X, Ding Y-J, et al. The Th17/Treg imbalance in patients with acute coronary syndrome. Clin. Immunol. 127(1), 89-97 (2008).

138. Zhao Z, Wu Y, Cheng M, et al. Activation of Th17/Th1 and Th1, but not Th17, 
is associated with the acute cardiac event in patients with acute coronary syndrome. Atherosclerosis. 217(2), 518-524 (2011).

139. Eid RE, Rao DA, Zhou J, et al. Interleukin-17 and interferon-gamma are produced concomitantly by human coronary artery-infiltrating T cells and act synergistically on vascular smooth muscle cells. Circulation [Internet]. 119(10), 1424-1432 (2009). Available from: http://www.ncbi.nlm.nih.gov/entrez/query.fcgi?cmd=Retrieve\&db=PubMe $\mathrm{d} \& \mathrm{dopt}=$ Citation\&list_uids $=19255340$.

140. Simon T, Taleb S, Danchin N, et al. Circulating levels of interleukin-17 and cardiovascular outcomes in patients with acute myocardial infarction. Eur. Heart J. 34(8), 570-577 (2013).

141. Young MS, Horn EJ, Cather JC. The ACCEPT study: ustekinumab versus etanercept in moderate-to-severe psoriasis patients. Expert Rev. Clin. Immunol. [Internet]. 7(1), 9-13 (2011). Available from: http://www.ncbi.nlm.nih.gov/pubmed/21162644.

142. Mease PJ, McInnes IB, Kirkham B, et al. Secukinumab Inhibition of Interleukin-17A in Patients with Psoriatic Arthritis. N. Engl. J. Med. [Internet]. 373(14), 1329-1339 (2015). Available from: http://www.nejm.org/doi/abs/10.1056/NEJMoa1412679.

143. Ryan C, Leonardi CL, Krueger JG, et al. Association between biologic therapies for chronic plaque psoriasis and cardiovascular events: a metaanalysis of randomized controlled trials. JAMA. 306(8), 864-871 (2011).

144. Pastrana JL, Sha X, Virtue A, et al. Regulatory T cells and Atherosclerosis. J. Clin. Exp. Cardiolog. [Internet]. 2012(Suppl 12), 2 (2012). Available from: http://www.pubmedcentral.nih.gov/articlerender.fcgi?artid=3757946\&tool $=$ pmcentrez\&rendertype $=$ abstract.

145. de Boer OJ, van der Meer JJ, Teeling P, van der Loos CM, van der Wal AC. Low numbers of FOXP3 positive regulatory T cells are present in all developmental stages of human atherosclerotic lesions. PLoS One [Internet]. 2(1), e779 (2007). Available from: http://www.ncbi.nlm.nih.gov/entrez/query.fcgi?cmd=Retrieve\&db=PubMe $\mathrm{d} \&$ dopt=Citation\&list_uids $=17712427$.

146. Maganto-Garcia E, Tarrio ML, Grabie N, Bu D, Lichtman AH. Dynamic changes in regulatory $\mathrm{T}$ cells are linked to levels of diet-induced hypercholesterolemia. Circulation. 124(2), 185-195 (2011).

147. Gräbner R, Lötzer K, Döpping S, et al. Lymphotoxin beta receptor signaling promotes tertiary lymphoid organogenesis in the aorta adventitia of aged ApoE-/- mice. J. Exp. Med. 206(1), 233-248 (2009).

148. Ait-Oufella $\mathrm{H}$, Salomon BL, Potteaux S, et al. Natural regulatory T cells control the development of atherosclerosis in mice. Nat Med [Internet]. 12(2), 178-180 (2006). Available from:

http://www.ncbi.nlm.nih.gov/entrez/query.fcgi?cmd=Retrieve\&db=PubMe $\mathrm{d} \& \mathrm{dopt}=$ Citation\&list_uids $=16462800$.

149. Taleb S, Tedgui A, Mallat Z. Regulatory T-cell immunity and its relevance to atherosclerosis. J Intern Med [Internet]. 263(5), 489-499 (2008). Available from: http://www.ncbi.nlm.nih.gov/entrez/query.fcgi?cmd=Retrieve\&db=PubMe $\mathrm{d} \& \mathrm{dopt}=$ Citation\&list_uids=18410592.

150. Weber C, Meiler S, Döring Y, et al. CCL17-expressing dendritic cells drive 
atherosclerosis by restraining regulatory T cell homeostasis in mice. J. Clin. Invest. 121(7), 2898-2910 (2011).

151. Nicoletti A, Paulsson G, Caligiuri G, Zhou X, Hansson GK. Induction of neonatal tolerance to oxidized lipoprotein reduces atherosclerosis in ApoE knockout mice. Mol. Med. [Internet]. 6(4), 283-90 (2000). Available from: http://www.pubmedcentral.nih.gov/articlerender.fcgi?artid=1949951\&tool =pmcentrez\&rendertype=abstract $\backslash$ nhttp://www.scopus.com/inward/recor d.url?eid=2-s2.0-0034170821\&partnerID=tZOtx3y1.

152. Ait-Oufella H, Horvat B, Kerdiles Y, et al. Measles virus nucleoprotein induces a regulatory immune response and reduces atherosclerosis in mice. Circulation [Internet]. 116(15), 1707-1713 (2007). Available from: http://www.ncbi.nlm.nih.gov/entrez/query.fcgi?cmd=Retrieve\&db=PubMe $\mathrm{d} \&$ dopt=Citation\&list_uids $=17875970$.

153. Klingenberg R, Lebens $M$, Hermansson A, et al. Intranasal immunization with an apolipoprotein B-100 fusion protein induces antigen-specific regulatory $\mathrm{T}$ cells and reduces atherosclerosis. Arter. Thromb Vasc Biol. 30(5), 946-952 (2010).

154. Li X, Liu Z, Yan X, et al. Induction of Regulatory T Cells by High-Dose gp96 Suppresses Murine Liver Immune Hyperactivation. PLoS One. 8(7) (2013).

155. Herbin $\mathrm{O}$, Ait-Oufella $\mathrm{H}, \mathrm{Yu} \mathrm{W}$, et al. Regulatory T-cell response to apolipoprotein B100-derived peptides reduces the development and progression of atherosclerosis in mice. Arter. Thromb Vasc Biol [Internet]. 32(3), 605-612. Available from: http://www.ncbi.nlm.nih.gov/entrez/query.fcgi?cmd=Retrieve\&db=PubMe $\mathrm{d} \&$ dopt=Citation\&list_uids $=22223728$.

156. Grundtman C, Jakic B, Buszko M, et al. Mycobacterial heat shock protein 65 (mbHSP65)-induced atherosclerosis: Preventive oral tolerization and definition of atheroprotective and atherogenic mbHSP65 peptides. Atherosclerosis. 242(1), 303-310 (2015).

157. Steinmetz M, Ponnuswamy P, Laurans L, Esposito B, Tedgui A, Mallat Z. The intravenous injection of oxidized LDL- or Apolipoprotein B100 - Coupled splenocytes promotes Th1 polarization in wildtype and Apolipoprotein E Deficient mice. Biochem. Biophys. Res. Commun. 464(1), 306-311 (2015).

158. Hermansson A, Ketelhuth DFJ, Strodthoff D, et al. Inhibition of T cell response to native low-density lipoprotein reduces atherosclerosis. J. Exp. Med. 207(5), 1081-1093 (2010).

159. Habets KLL, Van Puijvelde GHM, Van Duivenvoorde LM, et al. Vaccination using oxidized low-density lipoprotein-pulsed dendritic cells reduces atherosclerosis in LDL receptor-deficient mice. Cardiovasc. Res. 85(3), 622630 (2010).

160. Hjerpe C, Johansson D, Hermansson A, Hansson GK, Zhou X. Dendritic cells pulsed with malondialdehyde modified low density lipoprotein aggravate atherosclerosis in Apoe-/- mice. Atherosclerosis. 209(2), 436-441 (2010).

161. Choi JH, Cheong C, Dandamudi DB, et al. Flt3 signaling-dependent dendritic cells protect against atherosclerosis. Immunity. 35(5), 819-831 (2011).

162. Sage AP, Murphy D, Maffia P, et al. MHC Class II-restricted antigen presentation by plasmacytoid dendritic cells drives proatherogenic $\mathrm{T}$ cell immunity. Circulation. 130(16), 1363-1373 (2014).

163. Ait-Oufella H, Sage AP, Mallat Z, Tedgui A. Adaptive (T and B Cells) immunity 
and control by dendritic cells in atherosclerosis. Circ. Res. 114(10), 16401660 (2014).

164. Hermansson A, Johansson DK, Ketelhuth DFJ, Andersson J, Zhou X, Hansson GK. Immunotherapy with tolerogenic apolipoprotein B-100-loaded dendritic cells attenuates atherosclerosis in hypercholesterolemic mice. Circulation. 123(10), 1083-1091 (2011).

165. Dinh TN, Kyaw TS, Kanellakis P, et al. Cytokine therapy with interleukin2/anti-interleukin-2 monoclonal antibody complexes expands CD4+CD25+Foxp3+ regulatory T cells and attenuates development and progression of atherosclerosis. Circulation. 126(10), 1256-1266 (2012).

166. Dietrich T, Hucko T, Schneemann C, et al. Local delivery of IL-2 reduces atherosclerosis via expansion of regulatory T cells. Atherosclerosis. 220(2), 329-336 (2012).

167. Mor A, Luboshits G, Planer D, Keren G, George J. Altered status of CD4+CD25+ regulatory T cells in patients with acute coronary syndromes. Eur. Heart J. 27(21), 2530-2537 (2006).

168. Hasib L, Lundberg AK, Zachrisson H, Ernerudh J, Jonasson L. Functional and homeostatic defects of regulatory T cells in patients with coronary artery disease. J. Intern. Med. 279(1), 63-77 (2016).

169. Emoto T, Sasaki N, Yamashita T, et al. Regulatory/effector T-cell ratio is reduced in coronary artery disease. Circ. J. [Internet]. 78(12), 2935-41 (2014). Available from: http://www.ncbi.nlm.nih.gov/pubmed/25327882.

170. Wigren $M$, Björkbacka $H$, Andersson L, et al. Low levels of circulating CD4+FoxP3+ T cells are associated with an increased risk for development of myocardial infarction but not for stroke. Arterioscler. Thromb. Vasc. Biol. 32(8), 2000-2007 (2012).

171. Dietel B, Cicha I, Voskens CJ, Verhoeven E, Achenbach S, Garlichs CD. Decreased numbers of regulatory $\mathrm{T}$ cells are associated with human atherosclerotic lesion vulnerability and inversely correlate with infiltrated mature dendritic cells. Atherosclerosis. 230(1), 92-99 (2013).

172. Singer BD, King LS, D’Alessio FR. Regulatory T cells as immunotherapy. Front. Immunol. 5(FEB) (2014).

173. Marek-Trzonkowska N, Myśliwiec M, Dobyszuk A, et al. Therapy of type 1 diabetes with CD4(+)CD25(high)CD127(-) regulatory T cells prolongs survival of pancreatic islets - results of one year follow-up. Clin. Immunol. [Internet]. (2014). Available from: http://www.ncbi.nlm.nih.gov/pubmed/24704576.

174. Trzonkowski P, Bieniaszewska M, Juścińska J, et al. First-in-man clinical results of the treatment of patients with graft versus host disease with human ex vivo expanded CD4+CD25+CD127- T regulatory cells. Clin. Immunol. 133(1), 22-26 (2009).

175. Chistiakov DA, Sobenin IA, Orekhov AN, Bobryshev Y V. Dendritic cells in atherosclerotic inflammation: The complexity of functions and the peculiarities of pathophysiological effects. Front. Physiol. 5 MAY (2014).

176. Koreth J, Matsuoka K, Kim HT, et al. Interleukin-2 and regulatory T cells in graft-versus-host disease. N. Engl. J. Med. [Internet]. 365(22), 2055-66 (2011). Available from:

http://www.ncbi.nlm.nih.gov/pubmed/22129252\nhttp://www.pubmedce ntral.nih.gov/articlerender.fcgi?artid=PMC3727432. 
177. Saadoun D, Rosenzwajg M, Joly F, et al. Regulatory T-cell responses to lowdose interleukin-2 in HCV-induced vasculitis. N. Engl. J. Med. 365(22), 206777 (2011). *References 176 and 177 highlight the safety and efficacy of low dose IL2 in increasing the number of Tregs and limiting exaggerated immune responses. Low dose IL2 therapy is one of the most promising strategy that could dampen detrimental immune responses in several settings of immune-mediated diseases, including cardiovascular disease.

178. Ponnuswamy P, Van Vre EA, Mallat Z, Tedgui A. Humoral and cellular immune responses in atherosclerosis: spotlight on B- and T-cells. Vasc. Pharmacol [Internet]. 56(5-6), 193-203 (2012). Available from: http://www.ncbi.nlm.nih.gov/entrez/query.fcgi?cmd=Retrieve\&db=PubMe $\mathrm{d} \&$ dopt=Citation\&list_uids $=22329947$.

179. Paigen B, Morrow A, Brandon C, Mitchell D, Holmes P. Variation in susceptibility to atherosclerosis among inbred strains of mice. Atherosclerosis [Internet]. 57(1), 65-73 (1985). Available from: http://www.ncbi.nlm.nih.gov/entrez/query.fcgi?cmd=Retrieve\&db=PubMe $\mathrm{d} \& d o p t=$ Citation\&list_uids $=3841001$.

180. Huber S a, Sakkinen P, David C, Newell MK, Tracy RP. T helper-cell phenotype regulates atherosclerosis in mice under conditions of mild hypercholesterolemia. Circulation. 103(21), 2610-2616 (2001).

181. King VL, Szilvassy SJ, Daugherty A. Interleukin-4 deficiency decreases atherosclerotic lesion formation in a site-specific manner in female LDL receptor-/- mice. Arterioscler. Thromb. Vasc. Biol. 22(3), 456-461 (2002).

182. King VL, Cassis LA, Daugherty A. Interleukin-4 does not influence development of hypercholesterolemia or angiotensin II-induced atherosclerotic lesions in mice. Am. J. Pathol. [Internet]. 171(6), 2040-7 (2007). Available from: http://www.pubmedcentral.nih.gov/articlerender.fcgi?artid=2111126\&tool $=$ pmcentrez\&rendertype $=$ abstract.

183. Davenport P, Tipping PG. The Role of Interleukin-4 and Interleukin-12 in the Progression of Atherosclerosis in Apolipoprotein E-Deficient Mice. Am. J. Pathol. [Internet]. 163(3), 1117-1125 (2003). Available from: http://www.pubmedcentral.nih.gov/articlerender.fcgi?artid=1868277\&tool $=$ pmcentrez\&rendertype $=$ abstract.

184. Lin Y, Chen Z, Kato S. Receptor-selective IL-4 mutein modulates inflammatory vascular cell phenotypes and attenuates atherogenesis in apolipoprotein E-knockout mice. Exp. Mol. Pathol. 99(1), 116-127 (2015).

185. Binder CJ, Hartvigsen $\mathrm{K}$, Chang MK, et al. IL-5 links adaptive and natural immunity specific for epitopes of oxidized LDL and protects from atherosclerosis. J. Clin. Invest. 114(3), 427-437 (2004).

186. Miller AM, Xu D, Asquith DL, et al. IL-33 reduces the development of atherosclerosis. J. Exp. Med. [Internet]. 205(2), 339-46 (2008). Available from:

http://www.pubmedcentral.nih.gov/articlerender.fcgi?artid=2271006\&tool $=$ pmcentrez\&rendertype $=$ abstract.

187. Cardilo-Reis L, Gruber S, Schreier SM, et al. Interleukin-13 protects from atherosclerosis and modulates plaque composition by skewing the macrophage phenotype. EMBO Mol. Med. 4(10), 1072-1086 (2012).

188. Mallat Z, Besnard S, Duriez M, et al. Protective role of interleukin-10 in 
atherosclerosis. Circ Res [Internet]. 85(8), e17-24 (1999). Available from: http://www.ncbi.nlm.nih.gov/entrez/query.fcgi?cmd=Retrieve\&db=PubMe $\mathrm{d} \&$ dopt=Citation\&list_uids $=10521249$.

189. Nishihira K, Imamura T, Yamashita A, et al. Increased expression of interleukin-10 in unstable plaque obtained by directional coronary atherectomy. Eur. Heart J. 27(14), 1685-1689 (2006).

190. Ammirati E, Moroni F, Magnoni M, Camici PG. The role of T and B cells in human atherosclerosis and atherothrombosis. Clin. Exp. Immunol. [Internet]. 179(2), 173-187 (2015). Available from: http://onlinelibrary.wiley.com/doi/10.1111/cei.12477/abstract \nhttp://o nlinelibrary.wiley.com.libaccess.lib.mcmaster.ca/doi/10.1111/cei.12477/ab stract \nhttp://onlinelibrary.wiley.com.libaccess.lib.mcmaster.ca/store/10.1 111/cei.12477/asset/cei12477.pdf?v=1.

191. Jha HC, Divya A, Prasad J, Mittal A. Plasma circulatory markers in male and female patients with coronary artery disease. Heart Lung [Internet]. 39(4), 296-303 (2010). Available from: http://dx.doi.org/10.1016/j.hrtlng.2009.10.005.

192. Mirhafez SR, Zarifian A, Ebrahimi M, et al. Relationship between serum cytokine and growth factor concentrations and coronary artery disease. Clin. Biochem. 48(9), 575-580 (2015).

193. Ibc T, Consortium CAD. Large-Scale Gene-Centric Analysis Identifies Novel Variants for Coronary Artery Disease. PLoS Genet. 7(9), e1002260 (2011).

194. Sampi M, Ukkola O, Paivansalo M, Kesaniemi YA, Binder CJ, Horkko S. Plasma interleukin-5 levels are related to antibodies binding to oxidized low-density lipoprotein and to decreased subclinical atherosclerosis. J. Am. Coll. Cardiol. 52(17), 1370-1378 (2008).

195. Silveira A, McLeod O, Strawbridge RJ, et al. Plasma IL-5 concentration and subclinical carotid atherosclerosis. Atherosclerosis. 239(1), 125-130 (2015).

196. McLeod O, Silveira A, Valdes-Marquez E, et al. Genetic loci on chromosome 5 are associated with circulating levels of interleukin-5 and eosinophil count in a European population with high risk for cardiovascular disease. Cytokine. 81, 1-9 (2016).

197. Ishigami T, Abe K, Aoki I, et al. Anti-interleukin-5 and multiple autoantibodies are associated with human atherosclerotic diseases and serum interleukin-5 levels. FASEB J. 27(9), 3437-3445 (2013).

198. Garcia G, Taillé C, Laveneziana P, Bourdin A, Chanez P, Humbert M. Antiinterleukin-5 therapy in severe asthma. Eur. Respir. Rev. 22(129), 251-257 (2013).

199. Van Gool F, Molofsky AB, Morar MM, et al. Interleukin-5 - Producing group 2 innate lymphoid cells control eosinophilia induced by interleukin-2 therapy. Blood. 124(24), 3572-3576 (2014).

200. Fisher EA. Regression of Atherosclerosis: The Journey From the Liver to the Plaque and Back. Arterioscler. Thromb. Vasc. Biol. 36(2), 226-235 (2016). 
Table 1: Clinical trials targeting innate immune response

\begin{tabular}{|c|c|c|c|c|c|c|c|}
\hline Target & Drug & Clinical trial & Disease & $\mathrm{N}$ & Follow up & Dose & Result \\
\hline \multirow[t]{4}{*}{ IL1 } & Anakinra & $\begin{array}{l}\text { MRC-ILA Study } \\
\text { (Phase II) [35] }\end{array}$ & $\begin{array}{l}\text { Non-ST elevation ACS } \\
\text { patients, with less than } \\
\text { 48h with chest pain }\end{array}$ & 182 & 1 year & $\begin{array}{l}10 \mathrm{mg} \text { daily } 14 \\
\text { consecutive days }\end{array}$ & $\begin{array}{l}\text { Reduce CRP first } \\
\text { but then there is a } \\
\text { rebound } \\
\text { Increased CV } \\
\text { accidents }\end{array}$ \\
\hline & Canakinumab & Pilot Cantos [37] & $\begin{array}{l}\text { Diabetes Mellitus at } \\
\text { high CV risk }\end{array}$ & 556 & 4 months & $\begin{array}{l}5,15,50 \text { or } 50 \\
\mathrm{mg} / \mathrm{month}\end{array}$ & $\begin{array}{l}\text { Decreased hsCRP, } \\
\text { II6 and fibrinogen } \\
\text { Slight increase } \\
\text { triglycerides }\end{array}$ \\
\hline & Colchicine & [40] & ACS & 40 & $24 \mathrm{~h}$ & $\begin{array}{l}1 \mathrm{mg} \text { followed by } \\
0.5 \mathrm{mg} 6-24 \mathrm{~h} \\
\text { before } \\
\text { catheterization }\end{array}$ & $\begin{array}{l}\text { Decrease } \\
\text { transcoronary IL1 } \beta \text {, } \\
\text { IL18 and IL } 6 \text { but not } \\
\text { systemic levels }\end{array}$ \\
\hline & & {$[39]$} & $\begin{array}{l}\text { ACS or acute } \\
\text { ischaemic stroke }\end{array}$ & 80 & 30 days & $\begin{array}{l}1 \mathrm{mg} / \text { day vs } \\
\text { placebo }\end{array}$ & $\begin{array}{l}\text { Did not decrease } \\
\text { CRP }\end{array}$ \\
\hline Unknown & Methotrexate & CIRT [59] & $\begin{array}{l}\text { Prior MI and either with, } \\
\text { diabetes type } 2 \text { or } \\
\text { metabolic syndrome }\end{array}$ & 7,000 & $3-5$ years & $15-20 \mathrm{mg} / \mathrm{wk}$ & Ongoing \\
\hline 116 & Tocilizumab & \begin{tabular}{|l} 
Meta-analysis \\
(II6 Consortium) \\
{$[81,82]$}
\end{tabular} & RA & 139,449 & & $\begin{array}{l}4-8 \mathrm{mg} / \mathrm{kg} \text { every } 4 \\
\text { weeks }\end{array}$ & $\begin{array}{l}\text { IL6R rs7529229 variant } \\
\text { associated with } \\
\text { reduced CRP and } \\
\text { fibrinogen correlated } \\
\text { with tacilizumab }\end{array}$ \\
\hline
\end{tabular}




\begin{tabular}{|c|c|c|c|c|c|c|c|}
\hline & & $\begin{array}{l}\text { MEASURE } \\
\text { (Phase IV) [89] }\end{array}$ & $\begin{array}{l}\text { In RA patients already } \\
\text { treated with MTX }\end{array}$ & 132 & $8 \mathrm{mg} / \mathrm{kg}$ & 1 year & $\begin{array}{l}\text { No effect on } \\
\text { atherogenic small } \\
\text { dense LDL } \\
\text { Increased in non- } \\
\text { atherogenic LDL } \\
\text { Increase PON1 } \\
\text { Decrease sPLA } 2 \text { and } \\
\text { amiloyd A }\end{array}$ \\
\hline & & $\begin{array}{l}\text { Five core Phase } \\
\text { III [90] }\end{array}$ & RA patients & $\begin{array}{l}4,199 \\
\text { controls } \\
4,099 \\
\text { patients }\end{array}$ & $\begin{array}{l}8 \mathrm{mg} / \mathrm{kg} \text { to } \\
4 \mathrm{mg} / \mathrm{kg} \\
\text { depending } \\
\text { on side } \\
\text { effects }\end{array}$ & $1-3$ years & Decrease Ml \\
\hline & $\begin{array}{l}\text { Adalimumab } \\
\text { (ADA9 vs } \\
\text { Tocilizumab } \\
\text { (TCZ) }\end{array}$ & $\begin{array}{l}\text { ADACTA } \\
\text { (Phase IV) [88] }\end{array}$ & $\begin{array}{l}\text { MTX refractory RA } \\
\text { patients }\end{array}$ & $\begin{array}{l}163 \mathrm{TCZ} \\
162 \mathrm{ADA}\end{array}$ & $\begin{array}{l}8 \mathrm{mg} / \mathrm{kg} \\
(\mathrm{TCZ}) \\
40 \mathrm{mg} \text { ADA }\end{array}$ & 6 years & $\begin{array}{l}\text { Decrease CRP } \\
\text { Increase lipid levels }\end{array}$ \\
\hline \multirow[t]{3}{*}{ Lp-PLA 2} & Darapladib & Phase II [101] & in coronary patients & 959 & $\begin{array}{l}40,80 \text { or } \\
160 \mathrm{mg} / \text { day } \\
\text { for } 12 \\
\text { weeks }\end{array}$ & 12 weeks & $\begin{array}{l}\text { Decrease Lp-PLA } 2 \\
\text { Decrease } 116 \text { and } \\
\text { CRP }\end{array}$ \\
\hline & & $\begin{array}{l}\text { STABILITY } \\
{[103]}\end{array}$ & Stable CAD & 15,828 & $\begin{array}{l}160 \mathrm{mg} / \mathrm{day} \\
\text { or placebo }\end{array}$ & 3.7 years & $\begin{array}{l}\text { Failed in primary } \\
\text { endpoints, did not } \\
\text { decrease death due to } \\
\text { MI, stroke or CV } \\
\text { disease }\end{array}$ \\
\hline & & $\begin{array}{l}\text { SOLID-TIMI } 52 \\
{[104]}\end{array}$ & ACS & 13,026 & 160 mg/day & 2.5 years & $\begin{array}{l}\text { Failed in any primary } \\
\text { or secondary } \\
\text { endpoint }\end{array}$ \\
\hline
\end{tabular}




\begin{tabular}{|l|l|l|l|l|l|l|l|}
\hline SPLA2 & Varespladib & $\begin{array}{l}\text { PLASMA I } \\
\text { (Phase II) [118] }\end{array}$ & Stable CAD & 396 & $\begin{array}{l}\text { Decrease sPLA2-II, } \\
\text { oxLDL, hsCRP, LDL } \\
\text { size } \\
\text { Did not decrease } \\
\text { LDLlevels }\end{array}$ \\
\hline & $\begin{array}{l}\text { PLASMA II } \\
\text { (Phase II) [119] }\end{array}$ & Stable CAD & 197 & $\begin{array}{l}250 \text { or } 500 \\
\text { mg daily }\end{array}$ & 8 weeks \\
\hline & FRANCIS [120] & $\begin{array}{l}96 \text { hours of an ACS } \\
\text { event }\end{array}$ & 625 & $500 \mathrm{mg}$ & 6 months & $\begin{array}{l}\text { Decrease colesterol, } \\
\text { CRP and sPLAA2 } \\
\text { No effect in primary } \\
\text { endpoint }\end{array}$ \\
\hline & VISTA-16 [121] & $\begin{array}{l}\text { 96 hours of an ACS } \\
\text { event }\end{array}$ & 5,000 & $500 \mathrm{mg}$ & 6 months \\
\hline
\end{tabular}

